\title{
Inhibition of thioredoxin-interacting protein may enhance the therapeutic effect of dehydrocostus lactone in cardiomyocytes under doxorubicin stimulation via the inhibition of the inflammatory response
}

\author{
XUEZHI ZHANG ${ }^{*}$, CUIYU CHU* and YUANKUN HUANG \\ Department of Critical Care Medicine, Anqiu People's Hospital, Anqiu, Shandong 262100, P.R. China
}

Received October 6, 2021; Accepted December 10, 2021

DOI: $10.3892 /$ etm.2022.11150

\begin{abstract}
Heart failure (HF) is the leading cause of death around the world, the mortality caused by HF is growing rapidly, and has become a great threaten to both public health and economic growth. Dehydrocostus lactone (DHE) is the active constituent of Saussurea lappa and is widely used in traditional Chinese medicine for its multiple biological functions, including anti-inflammatory, antioxidant and anti-cancer. To the best of our knowledge, DHE's effect on HF has not been clarified. Thioredoxin-interacting protein (TXNIP) regulates the process of oxidative stress and inflammation and leads to an increase in oxidative stress via oxidization of thioredoxin, TXNIP promotes the activation of the immune response by its binding with the NOD-like receptor protein 3 inflammasome. An MTT assay revealed that the overexpression or inhibition of TXNIP markedly decreased or significantly increased the proliferation of H9c2 cells, respectively. Through reverse transcription-quantitative PCR (RT-qPCR) and western blotting, it was determined that the expression of proinflammatory cytokines was significantly decreased with the increased expression of anti-inflammatory cytokines in a TXNIP knockout model. Further study utilizing RT-qPCR and western blotting demonstrated that these effects may be mediated by the nuclear factor erythroid 2-related factor $2 /$ heme oxygenase- $1 / \mathrm{NF}-\kappa \mathrm{B}$ signaling pathway. In conclusion, TXNIP inhibition may promote the therapeutic effect of DHE on oxidative stress-induced damage.
\end{abstract}

Correspondence to: Dr Yuankun Huang, Department of Critical Care Medicine, Anqiu People's Hospital, 295 Jiankang Road, Anqiu, Shandong 262100, P.R. China

E-mail: DYG_cc@outlook.com

${ }^{*}$ Contributed equally

Key words: thioredoxin-interacting protein, dehydrocostus lactone, cardiomyocytes, doxorubicin, inflammation

\section{Introduction}

Heart failure (HF) is a cardiac disease induced by multiple factors, such as a high fat diet, lack of exercise and aging, that can be recognized by dysfunction in cardiac systolic and diastolic processes. The number of individuals affected by $\mathrm{HF}$ has increased from 5.7 million to 6.2 million in the US between 2013 and 2016, and HF-related deaths contributed to $13.4 \%$ of all deaths that occurred in the US in 2018 (1). Previous studies reported that proinflammatory cytokines serve a critical role in promoting the development of HF (2) and that an increased concentration of cytokines and biomarkers are exhibited in patients with HF (3). Inflammation has been regarded as a possible therapeutic target for patients with HF (4). Thus, pathways regulating inflammation and oxidative responses may act as a treatment method for reducing cardiovascular disease risk. Dehydrocostus lactone (DHE) is a natural sesquiterpene lactone and the major compound in the roots of a well-known traditional Chinese herbal medicine, Saussurea lappa. DHE has presented anti-inflammatory and immunomodulatory effects in previous studies $(5,6)$. A previous study also indicated that DHE protects HepG2 cells against oxidative stress via the induction of heme oxygenase-1 (HO-1) expression (7), and that this effect may be mediated by the inhibition of the $\mathrm{NF}-\kappa \mathrm{B}$ signaling pathway (8). Moreover, DHE has numerous biological functions, including anti-inflammatory properties, immunomodulatory capabilities and antitumor action (9). Previous studies found that DHE significantly inhibits the proliferation of cancer cells without affecting normal cells in breast and prostate cancer $(10,11)$. Another study indicated that DHE reduces lipopolysaccharide-induced acute lung injury in a rat model via the inhibition of the inflammatory response (12).

Thioredoxin-interacting protein (TXNIP) is a protein that serves a critical role in multiple cellular processes, including metabolism, growth and antioxidative responses, by inhibiting the ability of cells to take up glucose (13). Previous research has indicated that activation of the inflammatory response is mediated by the activation of TXNIP (14), thus, we hypothesized that TXNIP inhibition could enhance the therapeutic effect of DHE in cardiomyocytes. 
In the present study, a cell model of TXNIP overexpression and inhibition was established to study the proliferation of $\mathrm{H} 9 \mathrm{c} 2$ cells and the expression of pro and anti-inflammatory genes. The involvement of the nuclear factor erythroid 2-related factor 2 (Nrf2)/HO-1/NF- $\mathrm{BB}$ signaling pathway was also investigated.

\section{Materials and methods}

Vector constructions. The TXNIP cDNA fragment was obtained using PCR with the following primers: Forward, 5'-AGTGATTGGCAGCAGGTC-3' and reverse, 5'-GGTGTCTGGGATGTTTAGG-3'. A blank pcDNA3.1 vector (cat. no. HG-VPH0683; HonorGene) and the product obtained from PCR were digested with KpnI (cat. no. R3142S; New England BioLabs, Inc.) and XhoI (cat. no. R0146S; New England BioLabs, Inc.) enzymes and the TXNIP fragment was linked with the digested vector using T4 DNA Ligase (cat. no. M0202S; New England BioLabs, Inc.). The pcDNA3.1-TXNIP overexpression vector $(1.5 \mu \mathrm{g})$ was subsequently transfected into $\mathrm{H} 9 \mathrm{c} 2$ cells using Lipofectamine ${ }^{\mathrm{TM}} 3000$ Transfection Reagent (cat. no. L3000008; Thermo Fisher Scientific, Inc.) for $48 \mathrm{~h}$ at $37^{\circ} \mathrm{C}$ according to the manufacturer's protocol. Stable TXNIP-expressing H9c2 cells were screened using $1,000 \mu \mathrm{g} / \mathrm{ml} \mathrm{G} 418$. After four weeks of screening, stable TXNIP overexpression cells were obtained and cells were used to perform western blotting and ELISA experiments.

The TXNIP knockdown vector was constructed as previously described (15). The knockout of the TXNIP gene was performed using the CRISPR-Cas9 system. A blank lentiCRISPR v2 vector (cat. no. 52961; Addgene) was digested using the BsmBI (cat. no. R0580S; New England BioLabs, Inc.) enzyme as recommended according to previous study (15) and oligos were constructed using the following gRNAs: Forward, 5'-CACCGGAGACAGACACCCGCC CATC-3' and reverse, 5'-CGATGGGCGGGTGTCTGTCTC CAAA-3', designed using an online CRISPR design tool (CRISPRdirect; https://crispr.dbcls.jp). The digested vector and oligos were ligated using quick ligase (cat. no. M0201S; New England BioLabs, Inc.) to construct the TXNIP knockdown vector [target gene sequence: Forward, 5'-GATGGG CGGGTGTCTGTCTC-3' and reverse, 5'-GAGACAGAC ACCCGCCCATC-3'; target exon, TXNIP-202 (Transcript ID: ENSRNOT00000028793.7; domain affected, IPR011022 (InterPro database)]. The vector was first transfected into 293T cells to assemble lentiviruses using Lipofiter transfect reagent (cat. no. KS-TRLF-200; Hanbio Biotechnology Co., Ltd.) at $37^{\circ} \mathrm{C}$. The virus was collected at $72 \mathrm{~h}$, after which it was subsequently transduced into $\mathrm{H} 9 \mathrm{c} 2$ cells for $48 \mathrm{~h}$ at $37^{\circ} \mathrm{C}$. Stable TXNIP-knockout cells were screened using $2 \mu \mathrm{g} / \mathrm{ml}$ puromycin. The blank pcDNA3.1 vector was used as a blank control for TXNIP overexpression detection and the blank lentiCRISPR v2 vector was used as a blank control for TXNIP knockout detection.

Cell culture, grouping and MTT assay. The rat cardiomyoblast H9c2 (cat. no. CRL-1446) and the human kidney epithelial 293 T (cat. no. CRL-11268) cell lines were purchased from the American Type Culture Collection and cultured in high glucose DMEM (cat. no. 11965092; Thermo Fisher Scientific, Inc.) supplemented with $10 \%$ FBS (cat. no. 10091; Thermo Fisher Scientific, Inc.) in a $5 \% \mathrm{CO}_{2}$ humid atmosphere at $37^{\circ} \mathrm{C}$. Subsequently, the $\mathrm{H} 9 \mathrm{c} 2$ cells were divided into four groups: i) The control group (NC); ii) the DHE treatment group (OT); iii) the DHE treatment combined with TXNIP inhibition group (OI); and iv) the DHE treatment combined with TXNIP overexpression group $(\mathrm{OH})$. In all groups, $\mathrm{H} 9 \mathrm{c} 2$ cells were first treated with $5 \mu \mathrm{M}$ doxorubicin and incubated for $24 \mathrm{~h}$ at $37^{\circ} \mathrm{C}(16)$ with or without $30 \mu \mathrm{M}$ DHE for $24 \mathrm{~h}$ (17). The viability of cells was measured using an MTT assay. H9c2 cells were treated as described above, after which they were incubated with $5 \mathrm{mg} / \mathrm{ml} \mathrm{MTT} \mathrm{reagent} \mathrm{for} 4 \mathrm{~h}$ at $37^{\circ} \mathrm{C}$. Cells were then dissolved in DMSO and absorbance was detected at $490 \mathrm{~nm}$ using a microplate reader (cat. no. PT-3502C; Potenov).

Ethics statement. This study was carried out in strict accordance with the recommendations of the Guide for the Care and Use of Laboratory Animals of the National Institutes of Health (18). The experimental protocols were approved by the Ethics Committee of Animal Experiments of Anqiu People's Hospital (Anqiu, China). All experiments were conducted in accordance with the Declaration of Helsinki.

Mouse model and grouping. A total of 32 C57BL/6 mice (age, 8-10 weeks; weight, 24-27 g) were purchased from the Xiamen University Laboratory Animal Center. Mice were kept in a $22-24^{\circ} \mathrm{C}$ and $50-60 \%$ humidity atmosphere under a 12-h light/dark cycle, where food and water was freely available. Mice were randomly divided into the following four groups: i) The control group (NC); ii) the DHE treatment group (OT); iii) the DHE treatment combined with TXNIP inhibition group (OI); and iv) the DHE treatment combined with TXNIP overexpression group $(\mathrm{OH})$. In order to construct the TXNIP overexpression and knockout mouse model, $200 \mu \mathrm{l}$ of the TXNIP overexpression, knockout lentivirus vector or blank vector were injected in mice via the tail vein. The vector used for animal experiments was purchased from Hanbio Biotechnology Co., Ltd. A total of 32 mice were divided into two groups: The DHE-treated group $(n=20)$ and the TXNIP expression detection group $(n=12)$. Mice were treated with $15 \mathrm{mg} / \mathrm{kg}$ doxorubicin for 21 days to construct the HF model (19). In the DHE treatment groups, mice were treated with $5 \mathrm{mg} / \mathrm{kg}$ DHE for 21 days (12). For blood sample collection, $100 \mu \mathrm{l}$ blood was collected through ophthalmic vein into a $1.5 \mathrm{ml}$ tube, and incubated at room temperature for $1 \mathrm{~h}$. After centrifugation at $1,500 \mathrm{x} \mathrm{g}$ at $4^{\circ} \mathrm{C}$ for $10 \mathrm{~min}$, serum was collected and subjected to ELISA. Then, mice in each group were anesthetized using sodium pentobarbital $(100 \mathrm{mg} / \mathrm{kg})$ via intraperitoneal injection and then sacrificed by cervical dislocation. For heart tissue assessment, the expression of TXNIP in full heart tissue of mice without DHE treatment was detected using western blotting analysis. The full heart tissue of mice treated with DHE was collected after mice were sacrificed. Heart tissues were stored at $-80^{\circ} \mathrm{C}$ until further experimentation.

RNA extraction. RNA extraction was performed according to the protocol of the RNApure Tissue and Cell kit (cat. no. CW0560; CoWin Biosciences). Heart tissues and 
cells were first lysed with lysis buffer. After incubation at room temperature for $5 \mathrm{~min}$, the mixture was centrifuged at $13,000 \times \mathrm{g}, 4^{\circ} \mathrm{C}$ for $5 \mathrm{~min}$. Subsequently, the RNA samples were transferred into spin columns and centrifuged at $13,000 \mathrm{x} \mathrm{g}, 4^{\circ} \mathrm{C}$ for $1 \mathrm{~min}$. After washing with washing buffer, RNA samples were eluted from the spin column using elution buffer after centrifugation at $13,000 \mathrm{x} \mathrm{g}, 4^{\circ} \mathrm{C}$ for $1 \mathrm{~min}$. RNA sample concentration was detected using a spectrophotometer (UV5Nano; Mettler-Toledo International, Inc.). RNA samples were used for subsequent reverse transcription-quantitative PCR (RT-qPCR) experiments.

$R T$ - $q P C R$. RT-qPCR experiments were performed using an UltraSYBR One Step RT-qPCR kit according to the manufacturer protocol (cat. no. CW2623; CoWin Biosciences). The reaction mixture was prepared as recommended by the manufacturer protocol and the reaction was performed with the following steps: Reverse transcription at $45^{\circ} \mathrm{C}$ for $10 \mathrm{~min}$; initial denaturation at $95^{\circ} \mathrm{C}$ for $5 \mathrm{~min}$; and 40 cycles of denaturation at $95^{\circ} \mathrm{C}$ for $10 \mathrm{sec}$, annealing and elongation at $58^{\circ} \mathrm{C}$ for $10 \mathrm{sec}$ and final extension at $72^{\circ} \mathrm{C}$ for $30 \mathrm{sec}$. The primers used for qPCR were as follows: Inducible nitric oxide synthase (iNOS) forward, 5'-CCCTTCAATGGTTGGTACATGG-3' and reverse, 5'-ACATTGATCTCCGTGACAGCC-3'; TNF- $\alpha$ forward, 5'-TTCTCATTCCTGCTTGTGG-3' and reverse, 5'-ACTTGGTGGTTTGCTACG-3'; IL-6 forward, 5'-CCA CCAAGAACGATAGTCAA-3' and reverse, 5'-TTTCCACGA TTTCCCAGA-3'; IL-1 forward, 5'-CCAGCTTCAAATCTC ACAGCAG-3' and reverse, 5'-CTTCTTTGGGTATTGCTT GGGATC-3'; IL-10 forward, 5'-GGCAGATCTATGCTTGGC TCAGCACTG-3' and reverse, 5'-GCGATATCCCTGCAG TCCAGTAGACG-3'; cyclooxygenase-2 (COX-2) forward, 5'-TCACAGGCTTCCATTGACCAG-3' and reverse, 5'-CCG AGGCTTTTCTACCAGA-3'; NF-E2-Related Factor 2 (Nrf2) forward, 5'-GTCTTCACTGCCCCTCATC-3' and reverse, 5'-TCGGGAATGGAAAATAGCTCC-3'; HO-1 forward, 5'-AGAGTCCCTCACAGACAGAGTTT-3' and reverse, 5'-CCTGCAGAGAGAAGGCTACATGA-3'; NF- $\kappa$ B forward, 5'-ACGGGAGGGGAAGAAATCTATC-3' and reverse, 5'-AATGGCAAACTGTCTGTGAACA-3'; GAPDH forward, 5'-GATGCTGGTGCTGAGTATGTCG-3', reverse, 5'-GTG GTGCAGGATGCATTGCTCTGA-3'. GAPDH was used as an internal control. The expression of each target gene was calculated using $2^{-\Delta \Delta \mathrm{Cq}}$ method (20).

Western blotting. Heart tissues and cells from each group were lysed using RIPA lysis buffer (cat. no. CW2333; CoWin Biosciences) supplemented with a protease inhibitor cocktail (cat. no. CW2200; CWbio Biosciences). The concentration of proteins was determined using a BCA assay (cat. no. CW0014; CoWin Biosciences). Subsequently, $60 \mu \mathrm{g}$ protein/lane was separated by SDS-PAGE on a $10 \%$ gel. After electrophoresis, the proteins were transferred onto PVDF membranes through Trans-Blot (cat. no. 1703940; Bio-Rad Laboratories, Inc.) transfer blotter. The membranes were first incubated with 5\% skimmed milk for $1 \mathrm{~h}$ at room temperature, followed by incubation with the following primary antibodies at $4^{\circ} \mathrm{C}$ overnight (all, Abcam; all, 1:1,000): Kelch like ECH associated protein 1 (Keap1; cat.no.ab226997; 1:1,000),Nrf2 (cat.no.ab31163),HO-1 (cat. no. ab68477), inhibitor of nuclear factor $\kappa \mathrm{B}$ kinase (IKK; cat. no. ab178870), NF- $\kappa$ B (cat. no. ab32360), high mobility group box 1 (HMGB1; cat. no. ab18256), toll-like receptor (TLR)2 (cat. no. ab209217), TLR4 (cat. no. ab22048), IL-1 $\beta$ (cat. no. ab9722) and NLR family pyrin domain containing 3 (NLRP3; cat. no. ab263899), antibodies were purchased from Abcam). After washing with TBST (0.5\% Tween-20) for three times, the membranes were subsequently incubated with goat-anti rabbit and goat-anti mouse HRP-labeled secondary antibodies at room temperature (1:1,000; cat. nos. ab6721 and ab6789; Abcam) for $1 \mathrm{~h}$. The protein expression levels were detected using Immobilon Western HRP Substrate (cat. no. WBKLS0100; EMD Millpore) and were semi-quantified using Image Pro Plus 6.0 software (Media Cybernetics, Inc.). GAPDH was used as an internal control.

ELISA. ELISA was performed according to the protocol of each respective kit. The following kits were used and purchased from Abcam: iNOS (cat. no. ab285316), COX-2 (cat. no. ab210574), CCL9 (cat. no. ab240689), CXCL1 (cat. no. ab219044), CXCL9 (cat. no. ab203364), CXCL11 (cat. no. ab204519). Briefly, cultured medium and serum samples obtained from cells and mice were added to each well of a 96-well plate and incubated at room temperature for $3 \mathrm{~h}$. Then, after washing four times with washing buffer, the samples were incubated with antibodies included in each ELISA kit according to the manufacturer's protocol at room temperature for $1 \mathrm{~h}$, followed by incubation with HRP-streptavidin solution for $45 \mathrm{~min}$ at room temperature. After four incubations in washing buffer, the samples were incubated with one-step substrate reagent for $30 \mathrm{~min}$ at room temperature in the dark, then finally incubated with stop solution. The absorbance value was detected at $450 \mathrm{~nm}$.

Statistical analysis. Data are presented as the mean \pm SD. Experiments were repeated three times independently. The differences among groups were evaluated with one-way ANOVA and followed by Tukey's post hoc test. $\mathrm{P}<0.05$ was considered to indicate a statistically significant difference.

\section{Results}

Detection of H9c2 cell viability and expression of TXNIP in cell and mice model of HF. As presented in Fig. 1, the protein expression levels of TXNIP in the control (blank pcDNA3.1 vector), overexpression and control (blank lentiCRISPR v2) knockdown groups as well as the expression of TXNIP in the mice model of control, TXNIP overexpression and TXNIP knockout group, were detected using western blotting. The protein expression levels of TXNIP were significantly increased in the overexpression group and significantly decreased in the knockdown group compared with the controls $(\mathrm{P}<0.05$; Fig. 1A). And the viability rates of $\mathrm{H} 9 \mathrm{c} 2$ cells in the $\mathrm{NC}, \mathrm{OT}, \mathrm{OI}$ and $\mathrm{OH}$ groups were $100.0 \pm 8.8,115.6 \pm 9.3,142.2 \pm 13.3$ and $96.2 \pm 9.1$, respectively (Fig. 1B). The results indicated that the viability rate was significantly increased in the OI group but markedly reduced in the $\mathrm{OH}$ group compared with the $\mathrm{NC}$ group, which indicated that inhibition of TXNIP may serve a protective role in $\mathrm{H} 9 \mathrm{c} 2$ cells. The mRNA expression levels 
A
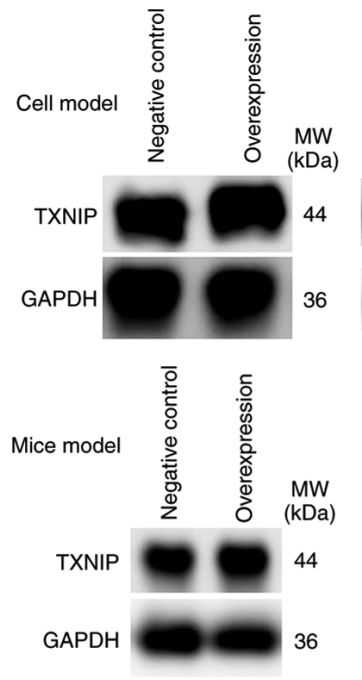
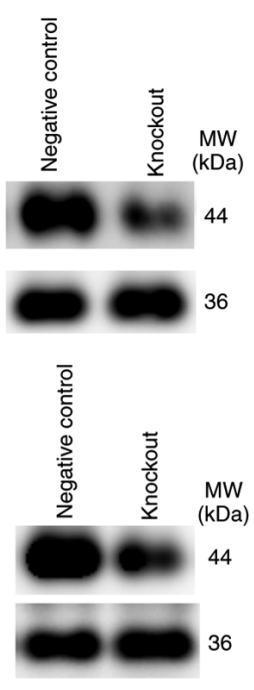

B
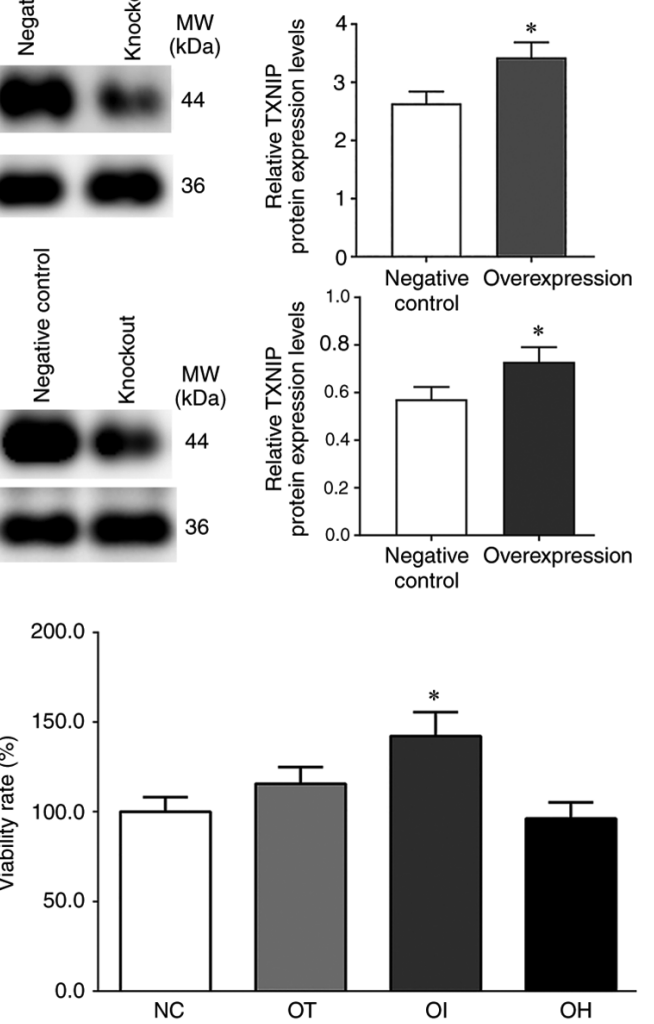
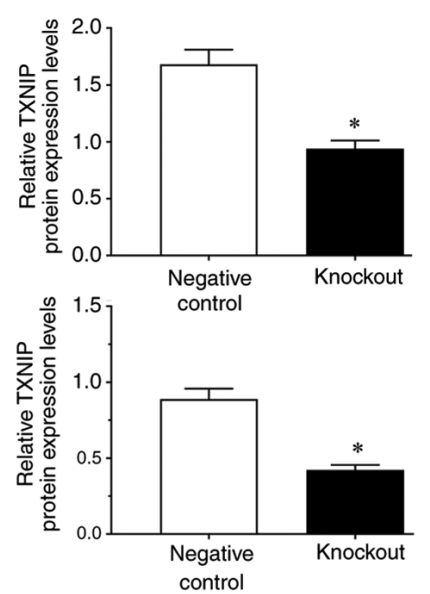
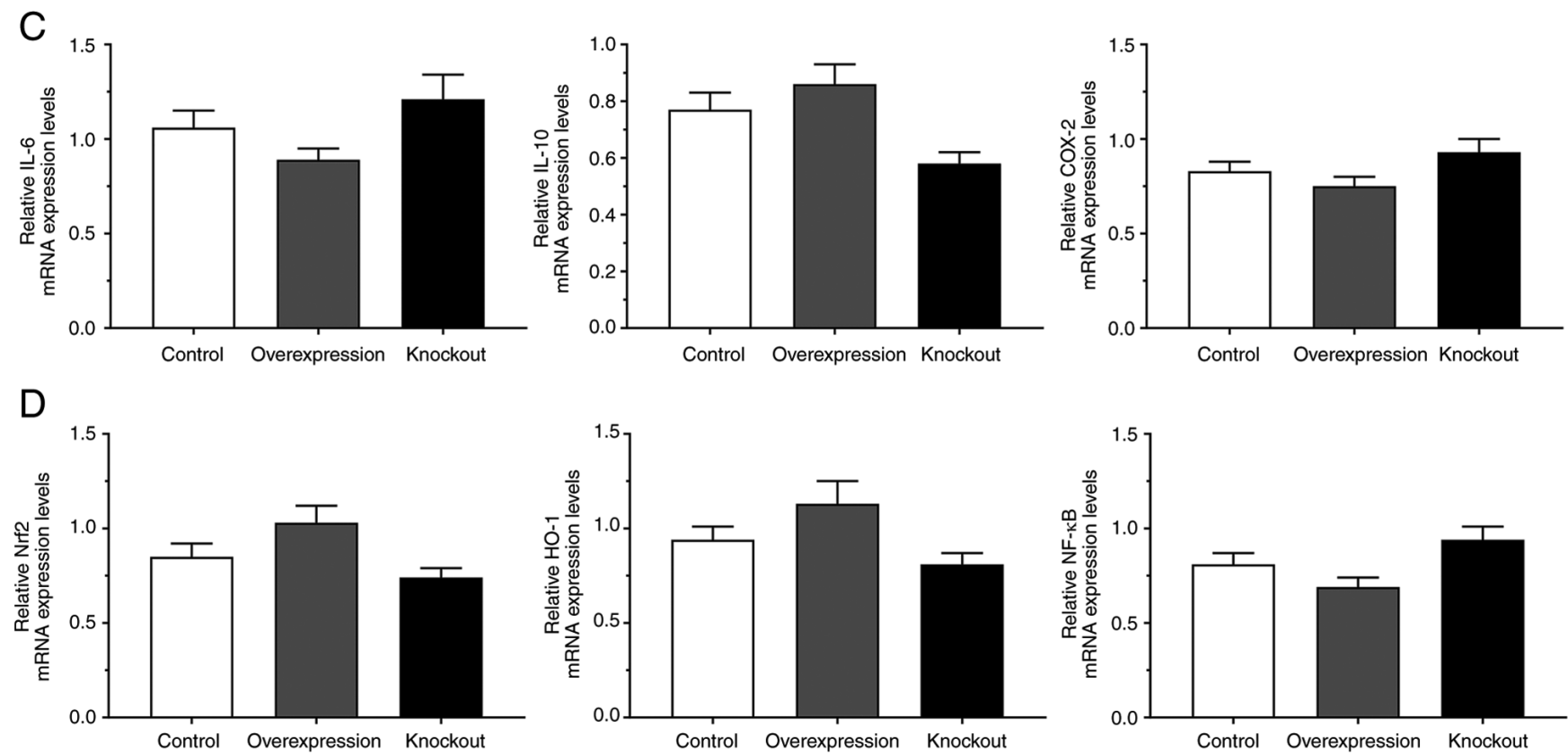

Figure 1. Evaluation of model construction using reverse transcription-quantitative PCR and western blotting, and cell viability rate assessment using an MTT assay. (A) TXNIP expression in overexpression and knockout groups without DHE treatment in H9c2 cells and mice. H9c2 cells and mice transfected with blank pcDNA3.1 vector were set as the negative control for the TXNIP overexpression group, and cells transfected with blank lantiCRISPR v2 vector were set as the negative control for the TXNIP knockout group. (B) DHE effect on H9c2 cell viability rate (\%) compared with the control group. (C) Expression of inflammatory related genes without DHE treatment. (D) Expression of Nrf2/HO-1 signaling pathway genes without DHE treatment. ${ }^{~ P}<0.05$ vs. control group. Data are presented as the mean \pm SD. Each experiment was repeated three times independently. DHE, dehydrocostus lactone; TXNIP, thioredoxin-interacting protein; Nrf2, nuclear factor erythroid 2-related factor 2; HO-1, heme oxygenase-1; NC, negative control; OT, DHE treatment group; OI, DHE treatment combined with the TXNIP inhibition group; OH, DHE treatment combined with the TXNIP overexpression group; COX-2, cyclooxygenase 2.

of inflammatory-related genes and $\mathrm{Nrf} 2 / \mathrm{HO}-1$ signaling pathway genes, such as IL-6, IL-10, COX-2, Nrf2, HO-1 and $\mathrm{NF}-\kappa \mathrm{B}$, in each group without DHE treatment was detected via RT-qPCR. Although the mRNA expression levels of these genes were slightly changed, no significant difference was observed (Fig. 1C and D). 
A

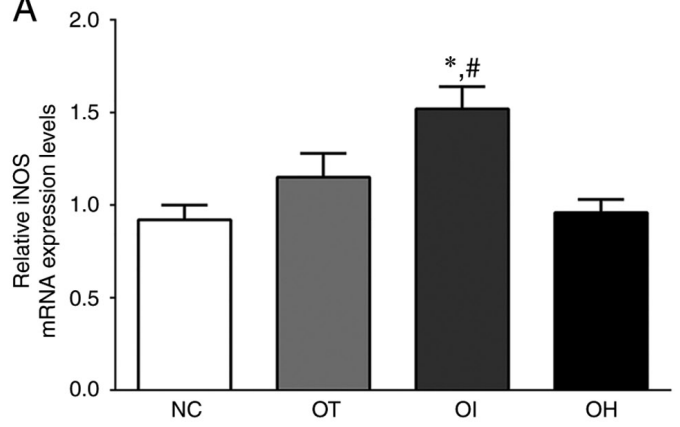

C

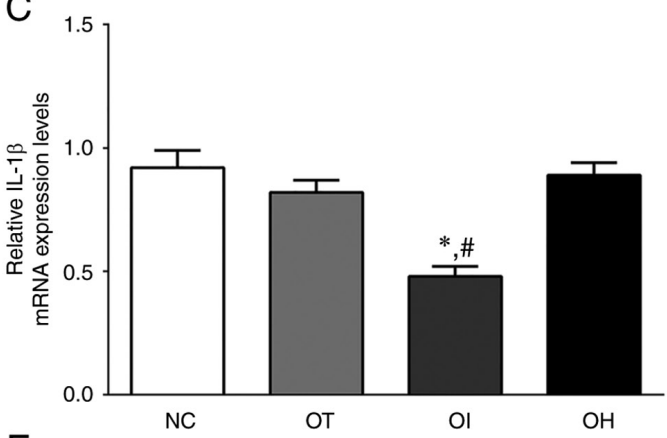

E

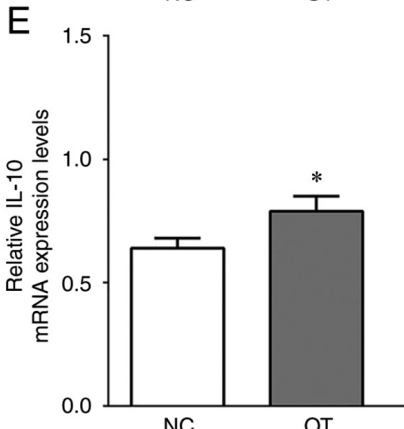

B

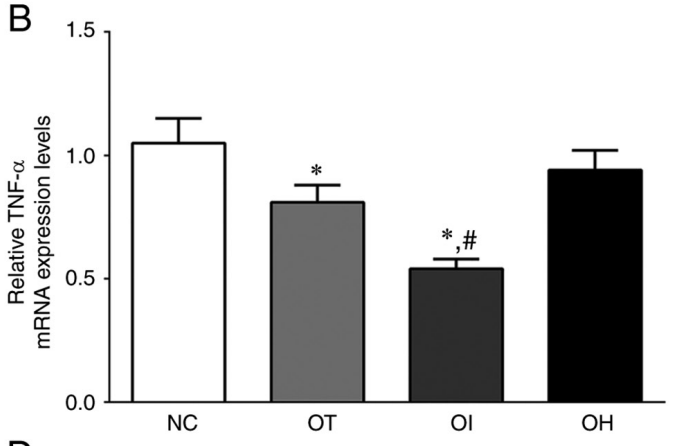

D

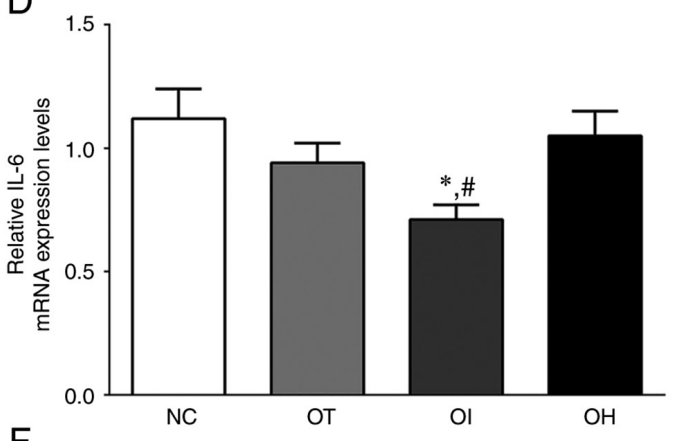

$\mathrm{F}$

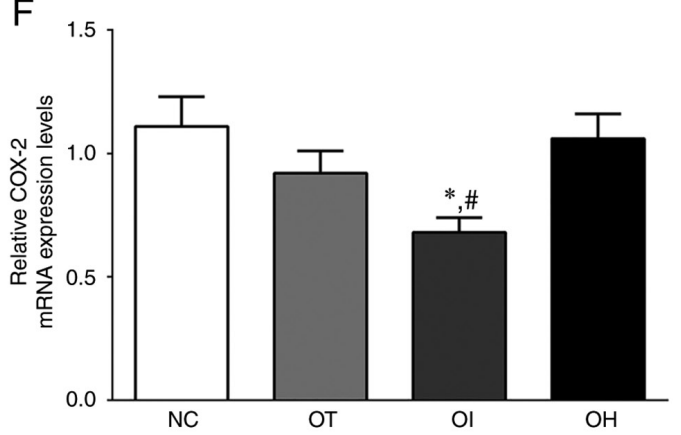

Figure 2. Expression levels of inflammation and oxidative-reduction related mRNA in H9c2 cells using reverse transcription-quantitative PCR. (A) iNOS, (B) TNF- $\alpha$, (C) IL-1, (D) IL-6, (E) IL-10 and (F) COX-2 in H9c2 cells. Data are presented as the mean \pm SD. Each experiment was repeated three times independently. ${ }^{*} \mathrm{P}<0.05$ vs. NC group; ${ }^{*} \mathrm{P}<0.05$ vs. OT group. DHE, dehydrocostus lactone; TXNIP, thioredoxin-interacting protein; NC, negative control; OT, DHE treatment group; OI, DHE treatment combined with the TXNIP inhibition group; OH, DHE treatment combined the with TXNIP overexpression group; iNOS, inducible nitric oxide synthase; COX-2, cyclooxygenase-2.

$m R N A$ expression levels of inflammation-related genes in mouse heart tissues and $\mathrm{H} 9 \mathrm{c} 2$ cells. As presented in Fig. 2, the expression levels of iNOS, TNF- $\alpha$, IL-1 $\beta$, IL-6, IL-10 and COX-2 mRNA in H9c2 cells of the NC, OT, OI and $\mathrm{OH}$ groups were detected using RT-qPCR. Briefly, the expression of iNOS mRNA was significantly increased in OI group compared with the NC and OT groups $(\mathrm{P}<0.05)$. The expression of TNF- $\alpha$ in these groups was significantly decreased in OT and OI group compared with NC group $(\mathrm{P}<0.05)$, and was significantly decreased in the OI group compared with the OT group $(\mathrm{P}<0.05)$. The expression of IL-1 $\beta$ in these groups was significantly decreased in the OI group compared with the NC and OT groups $(\mathrm{P}<0.05)$. IL-10 expression levels were significantly increased in the OT and OI groups compared with the $\mathrm{NC}$ group $(\mathrm{P}<0.05)$, and were significantly increased in the OI group compared with the OT group $(\mathrm{P}<0.05)$. The expression of COX-2 in these groups was also significantly decreased in the OI group compared with NC and OT groups $(\mathrm{P}<0.05)$.

As presented in Fig. 3, the expression of iNOS, TNF- $\alpha$, IL-1 $\beta$, IL-6, IL-10 and COX-2 mRNA in mice heart tissue of
$\mathrm{NC}$, OT, OI and $\mathrm{OH}$ group was detected using RT-qPCR. The expression of iNOS in these groups was significantly increased in the OI group compared with the NC and OT group $(\mathrm{P}<0.05)$. The expression of TNF- $\alpha$ in these groups was significantly decreased in the OT and OI groups compared with the $\mathrm{NC}$ group $(\mathrm{P}<0.05)$, and was significantly decreased in the OI group compared with the OT group $(\mathrm{P}<0.05)$. IL-1 $\beta$ expression levels were significantly decreased in the OI group compared with the $\mathrm{NC}$ and OT groups $(\mathrm{P}<0.05)$. Additionally, the expression of IL-6 in these groups was significantly decreased in the OT and OI groups compared with the NC group $(\mathrm{P}<0.05)$, and was significantly decreased in the OI group compared with the OT group $(\mathrm{P}<0.05)$. The expression of IL-10 in these groups was significantly increased in OT and OI group compared with the $\mathrm{NC}$ group $(\mathrm{P}<0.05)$, and was significantly increased in the OI group compared with the OT group $(\mathrm{P}<0.05)$. The expression of COX-2 in these groups was significantly decreased in OI group compared with the $\mathrm{NC}$ and OT groups $(\mathrm{P}<0.05)$. iNOS and IL-10 mRNA expression levels were significantly increased after TXNIP knockout compared with the $\mathrm{NC}$ and OT groups, whereas the expression 

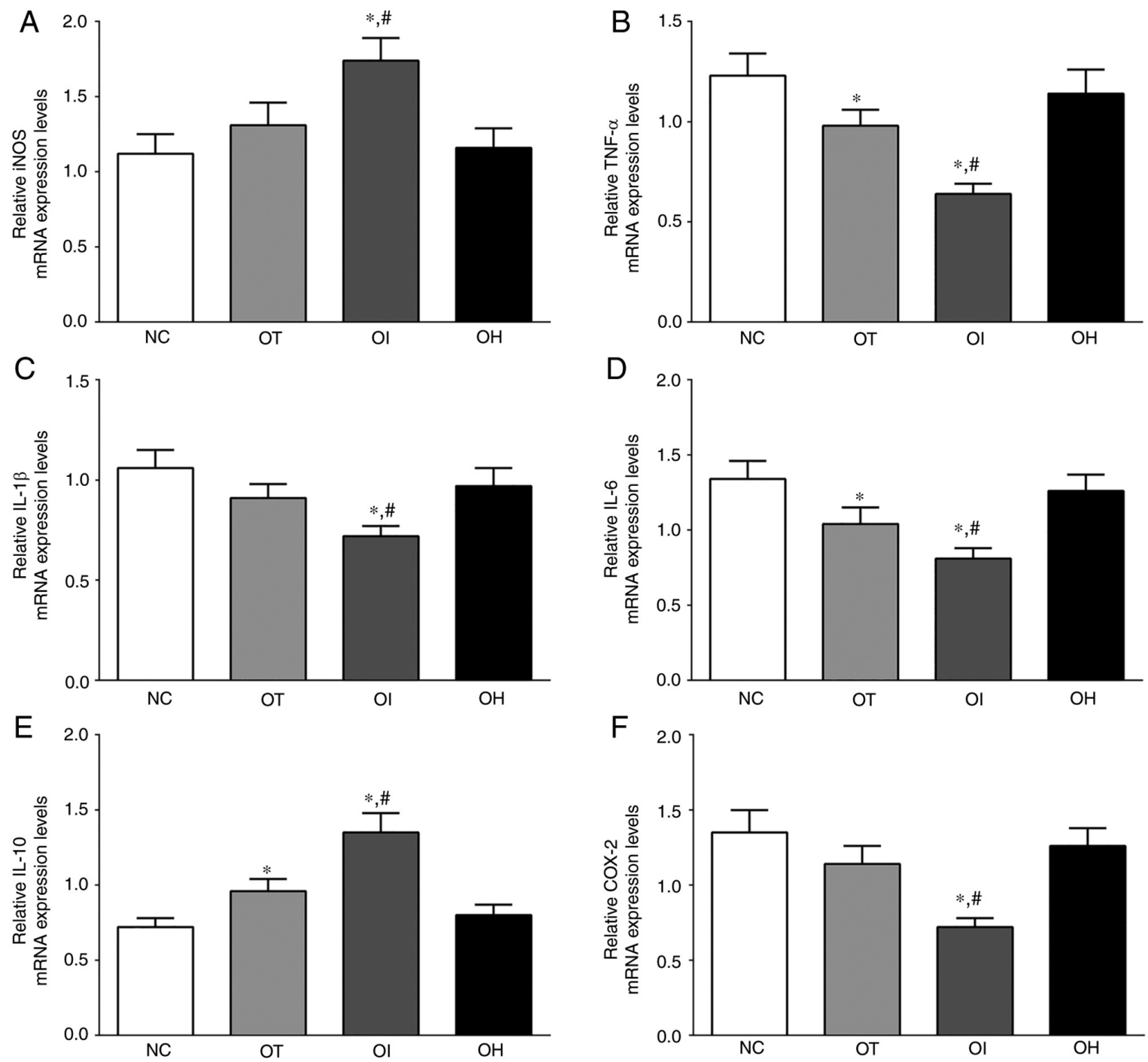

Figure 3. Expression levels of inflammation and oxidative-reduction related mRNA in heart tissue of mice using reverse transcription-quantitative PCR. (A) iNOS, (B) TNF- $\alpha$, (C) IL-1, (D) IL-6, (E) IL-10 and (F) COX-2 in mouse heart tissues. Data are presented as the mean \pm SD. Each experiment was repeated three times independently. ${ }^{*} \mathrm{P}<0.05$ vs. NC group; ${ }^{*} \mathrm{P}<0.05$ vs. OT group. DHE, dehydrocostus lactone; TXNIP, thioredoxin-interacting protein; NC, negative control; OT, DHE treatment group; OI, DHE treatment combined with TXNIP inhibition group; OH, DHE treatment combined with TXNIP overexpression group; iNOS, inducible nitric oxide synthase; COX-2, cyclooxygenase-2.

of proinflammatory factors, such as TNF- $\alpha$, IL-1 $\beta$, IL- 6 and COX-2, was decreased following TXNIP knockout compared with the NC and OT groups. The results indicated that inhibition of TXNIP reduced the inflammatory response in H9c2 cells and in mouse heart tissues.

Protein expression levels of the $\mathrm{HO}-1 / \mathrm{NF}-\kappa \mathrm{B}$ signaling pathway in mice heart tissues and $H 9 c 2$ cells. As presented in Fig. 4, the expression of the HO-1/NF- $\mathrm{kB}$ signaling pathway in $\mathrm{NC}, \mathrm{OT}$, OI and $\mathrm{OH}$ groups of $\mathrm{H} 9 \mathrm{c} 2$ cells was detected using western blotting. The expression of Keap1 in these groups was significantly decreased in OT and OI groups, while significantly increased in the $\mathrm{OH}$ group compared with the NC group $(\mathrm{P}<0.05)$. Levels were also significantly decreased in the OI group and significantly increased in the $\mathrm{OH}$ group compared with the OT group $(\mathrm{P}<0.05)$. The expression of Nrf2 was significantly increased in OT and OI groups compared with the $\mathrm{NC}$ group $(\mathrm{P}<0.05)$, and significantly increased in the OI group compared with OT group $(\mathrm{P}<0.05)$.
Additionally, the expression of HO-1 was significantly increased in OT and OI groups compared with the NC group $(\mathrm{P}<0.05)$, and significantly increased in the OI group and significantly decreased in the $\mathrm{OH}$ group compared with the OT group $(\mathrm{P}<0.05)$. The expression of IKK in these groups was significantly increased in all treatment groups compared with $\mathrm{NC}$ group $(\mathrm{P}<0.05)$, and was significantly increased in OI group compared with OT group $(\mathrm{P}<0.05)$. The expression of NF- $\mathrm{KB}$ in these groups was significantly decreased in OI group compared with $\mathrm{NC}$ and OT group $(\mathrm{P}<0.05)$, and was significantly increased in $\mathrm{OH}$ group compared with $\mathrm{NC}$ and OT group $(\mathrm{P}<0.05)$.

As presented in Fig. 5, the expression of $\mathrm{HO}-1 / \mathrm{NF}-\kappa \mathrm{B}$ signaling pathway in $\mathrm{NC}$, OT, OI and $\mathrm{OH}$ groups of heart tissues was detected using western blotting. The expression of Keap1 in these groups was significantly decreased in the OI group compared with NC and OT groups, and significantly decreased in the $\mathrm{OH}$ group compared with the $\mathrm{NC}$ group. The expression of $\mathrm{Nrf} 2$ in these groups was significantly increased 


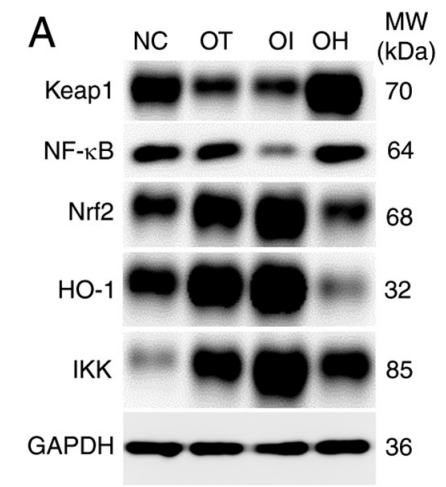

C
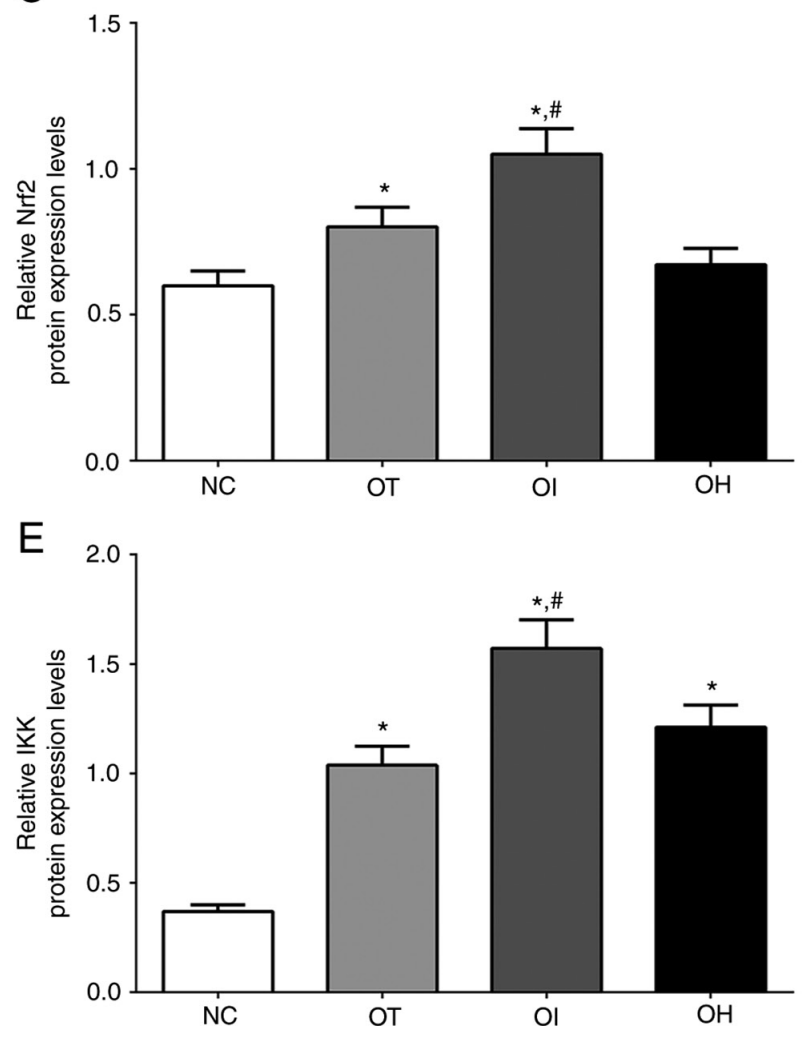
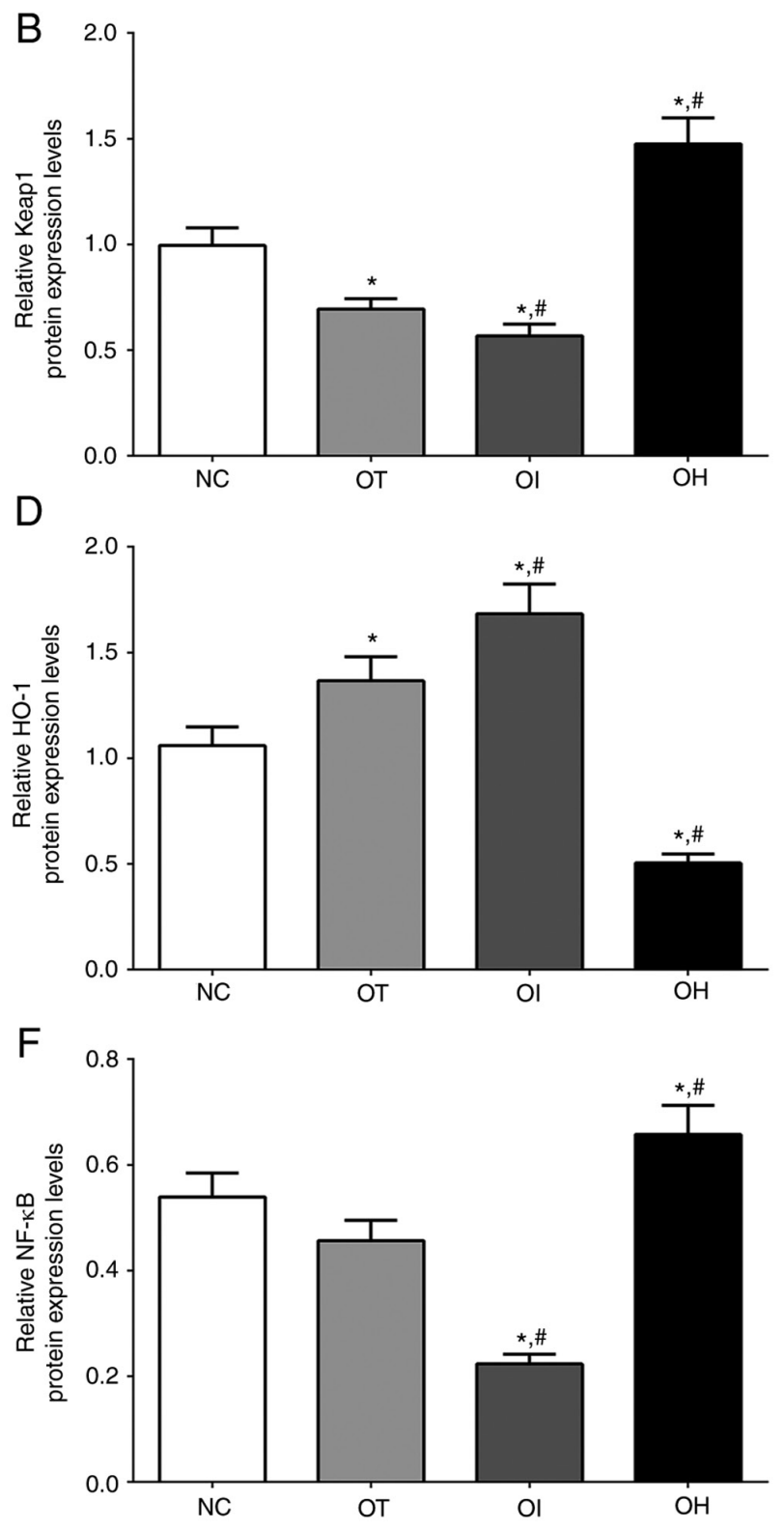

Figure 4. Protein expression levels of HO-1 regulator proteins in H9c2 cells using western blot method. (A) Western blotting analysis and quantitative analysis of (B) Keap1, (C) Nrf2, (D) HO-1, (E) IKK and (F) NF- $\kappa$ B in H9c2 cells. Data are presented as the mean \pm SD. Each experiment was repeated three times independently. ${ }^{*} \mathrm{P}<0.05$ vs. NC group. ${ }^{\#} \mathrm{P}<0.05$ vs. OT group. DHE, dehydrocostus lactone; TXNIP, thioredoxin-interacting protein; NC, negative control; OT, DHE treatment group; OI, DHE treatment combined with TXNIP inhibition group; OH, DHE treatment combined with TXNIP overexpression group; Nrf2, nuclear factor erythroid 2-related factor 2; HO-1, heme oxygenase-1; Keap1, Kelch-like ECH-associated protein 1; MW, molecular weight.

in the OI group compared with NC and OT groups, while significantly decreased in $\mathrm{OH}$ group compared with the $\mathrm{NC}$ and OT groups. The expression of $\mathrm{HO}-1$ in these groups was significantly increased in the OI group compared with the NC and the OT group. The expression of IKK in these groups was significantly increased in OT and OI group compared with the NC group, and was significantly increased in the OI group and significantly decreased in the $\mathrm{OH}$ group compared with the OT group. The expression of $\mathrm{NF}-\kappa \mathrm{B}$ in these groups was significantly decreased in the OI group compared with $\mathrm{NC}$ and OT groups.

These results indicated that, in both cells and mice, the $\mathrm{HO}-1 / \mathrm{NF}-\kappa \mathrm{B}$ signaling pathway was activated after TXNIP knockout, as the expression of HO-1 was significantly increased. It was therefore hypothesized that TXNIP knockout may have a protective role in $\mathrm{H} 9 \mathrm{c} 2$ cells and mouse heart tissues.

Protein expression levels of inflammation response-related molecules in mice heart tissues and $\mathrm{H} 9 \mathrm{c} 2$ cells. As presented in Fig. 6, the expression of HMGB1, TLR2, TLR4, IL-1 $\beta$ and NLRP3 in NC, OT, OI and $\mathrm{OH}$ group of $\mathrm{H} 9 \mathrm{c} 2$ cells were detected using western blotting. The expression of HMGB1 in these groups was significantly decreased in OT and OI group compared with $\mathrm{NC}$ group $(\mathrm{P}<0.05)$, and was significantly decreased in OI group and significantly increased in $\mathrm{OH}$ group compared with OT group $(\mathrm{P}<0.05)$. The expression of TLR2 in these groups was significantly decreased in OI group compared with NC and OT group $(\mathrm{P}<0.05)$, and was significantly increased in $\mathrm{OH}$ group compared with 
A
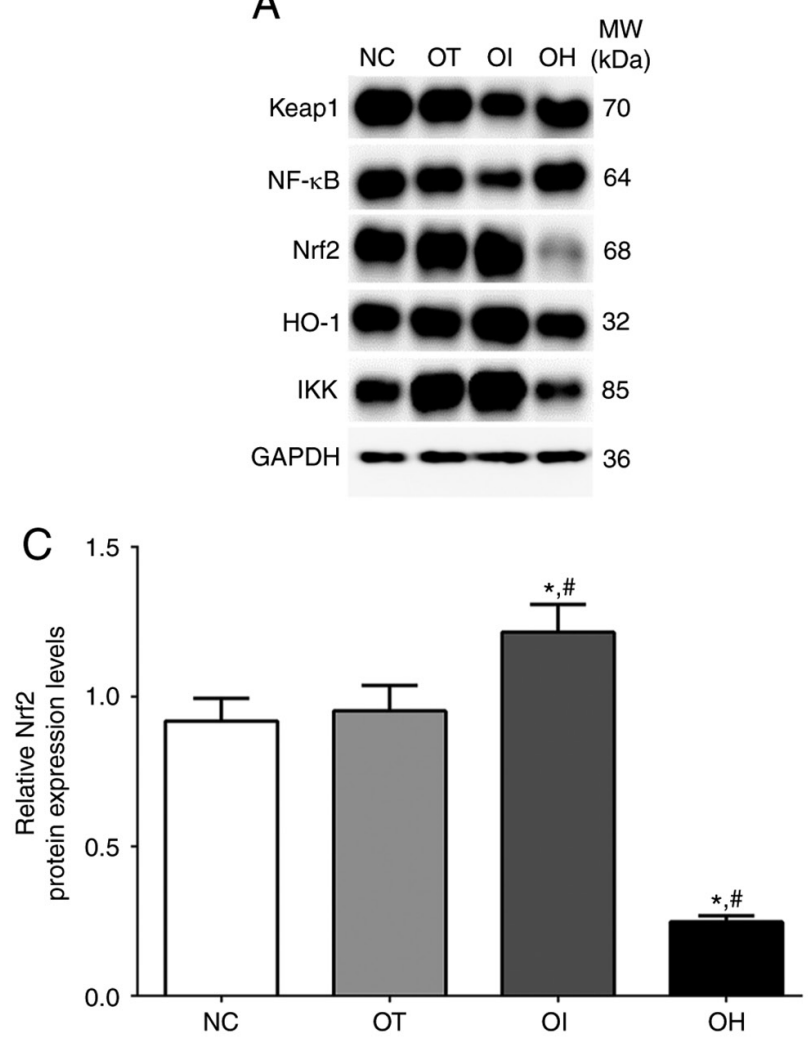

E

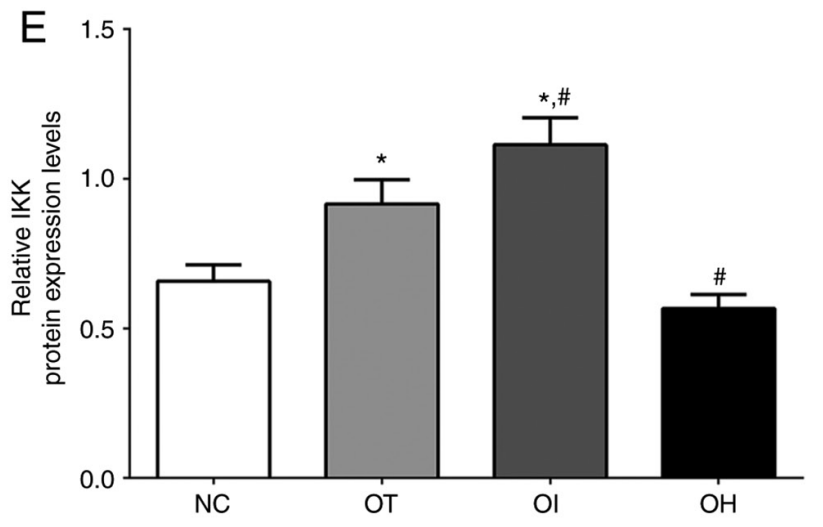

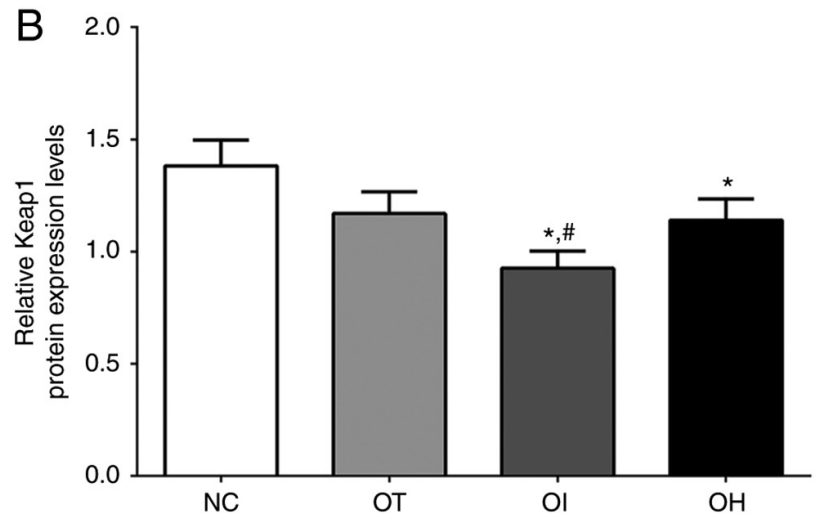
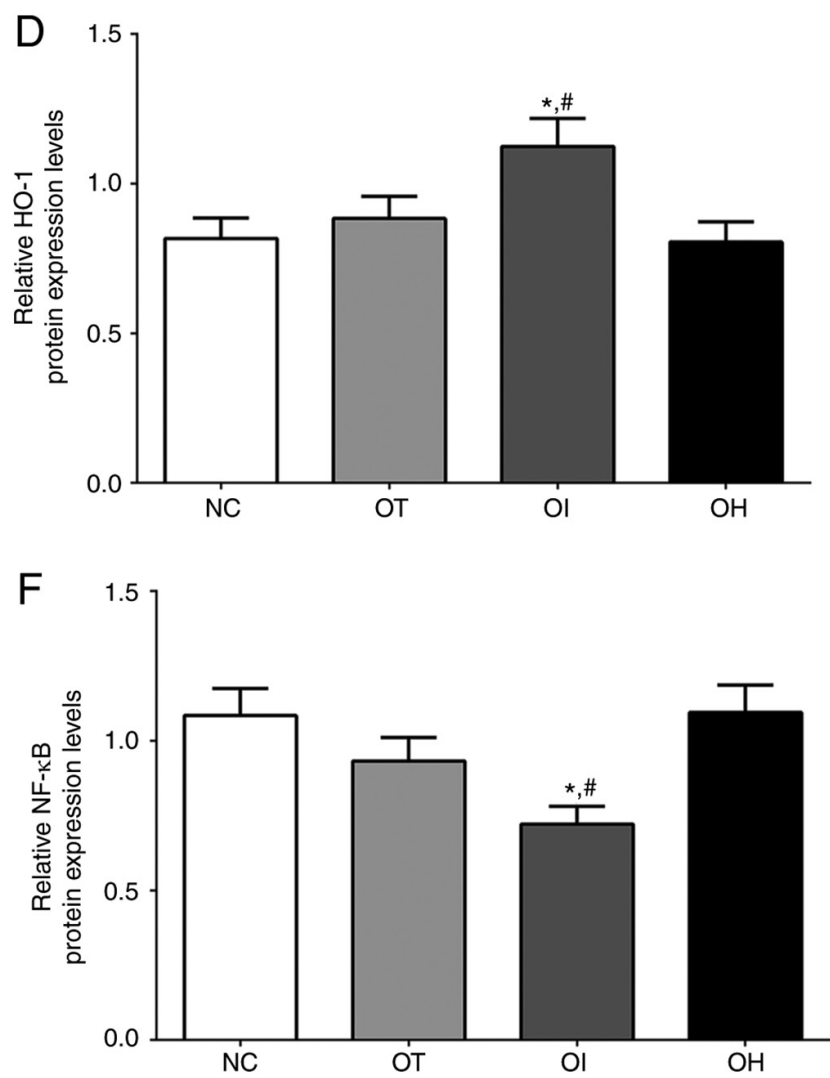

Figure 5. Protein expression levels of proinflammation proteins in heart tissue of mice using western blot method. (A) Western blotting analysis and quantitative analysis of (B) Keap1, (C) Nrf2, (D) HO-1, (E) IKK and (F) NF-кB. Data are presented as the mean \pm SD. Each experiment was repeated three times independently. ${ }^{*} \mathrm{P}<0.05$ vs. NC group. ${ }^{\text {"P}}<0.05$ vs. OT group. DHE, dehydrocostus lactone; TXNIP, thioredoxin-interacting protein; NC, negative control; OT, DHE treatment group; OI, DHE treatment combined with TXNIP inhibition group; OH, DHE treatment combined with TXNIP overexpression group; TLR, toll-like receptor; HMGB1, high mobility group protein B1; NLRP3, NOD-, LRR- and pyrin domain-containing protein 3; MW, molecular weight.

OT group $(\mathrm{P}<0.05)$. The expression of TLR4 in these groups was significantly decreased in OI group compared with NC and OT group $(\mathrm{P}<0.05)$, and was significantly increased in $\mathrm{OH}$ group compared with $\mathrm{NC}$ and $\mathrm{OT}$ group $(\mathrm{P}<0.05)$. The expression of IL-1 $\beta$ in these groups was significantly increased in $\mathrm{OH}$ group compared with $\mathrm{NC}$ and OT group $(\mathrm{P}<0.05)$. The expression of NLRP3 in these groups was significantly decreased in OI group compared with NC and OT group $(\mathrm{P}<0.05)$, and significantly increased in $\mathrm{OH}$ group compared with OT group $(\mathrm{P}<0.05)$.

As for mouse heart tissues (Fig. 7), the expression of HMGB1, TLR2, TLR4, IL-1 $\beta$ and NLRP3 in NC, OT, OI and $\mathrm{OH}$ group of heart tissues were detected using western blotting. The expression of HMGB1 in these groups was significantly deceased in OI group compared with $\mathrm{NC}$ and OT group $(\mathrm{P}<0.05)$, and significantly increased in $\mathrm{OH}$ group compared with NC and OT group $(\mathrm{P}<0.05)$. The expression of TLR 2 in these groups was significantly decreased in OI group compared with NC and OT group $(\mathrm{P}<0.05)$. The expression of TLR4 in these groups was significantly decreased in OT and OI group compared with NC group $(\mathrm{P}<0.05)$, and was significantly decreased in OI group compared with OT group and significantly increased in $\mathrm{OH}$ group compared with OT group $(\mathrm{P}<0.05)$. The expression of IL-1 $\beta$ in these groups was significantly decreased in OT and OI group compared with NC group $(\mathrm{P}<0.05)$, and was significantly decreased in OI group and significantly increased in $\mathrm{OH}$ group compared with $\mathrm{OT}$ group $(\mathrm{P}<0.05)$. 


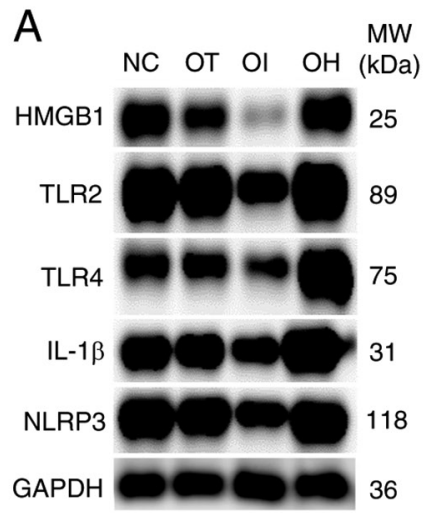

C
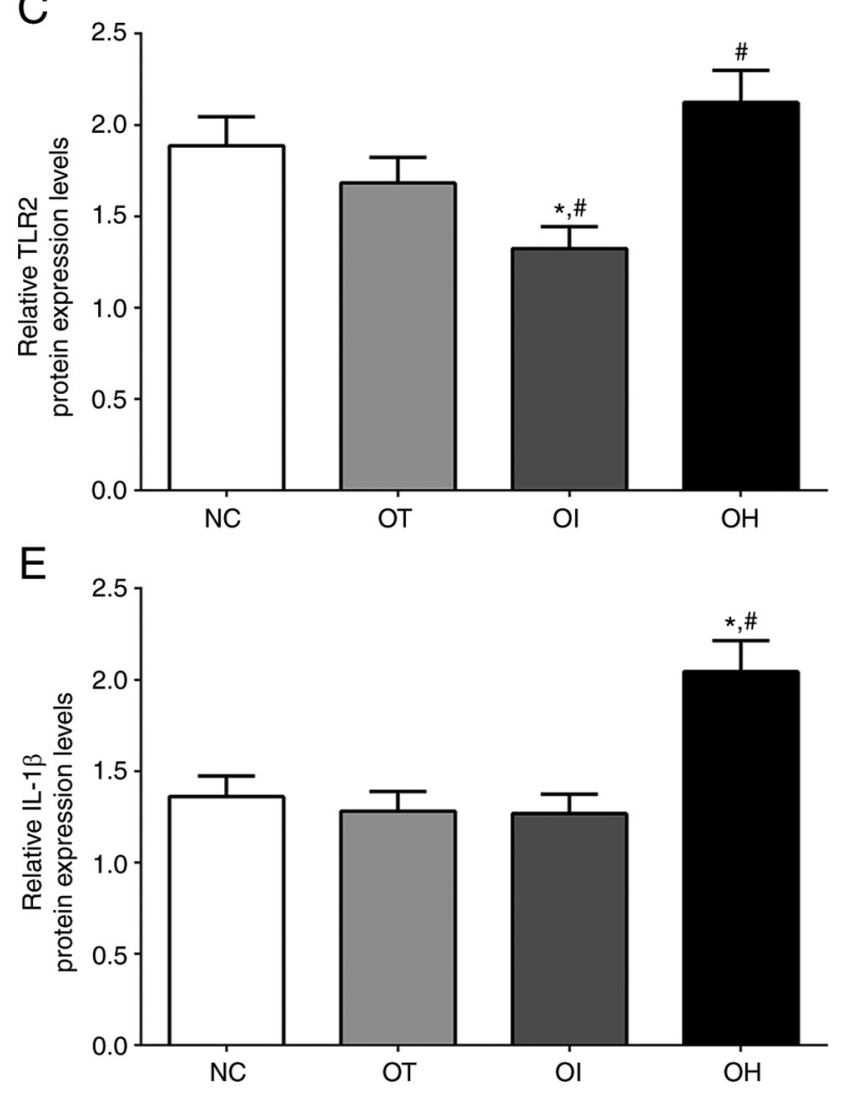

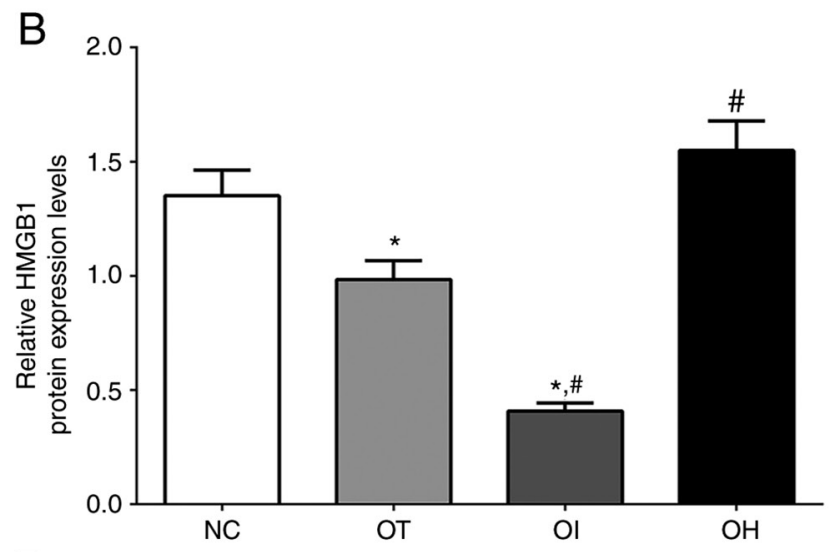

$\mathrm{D}$

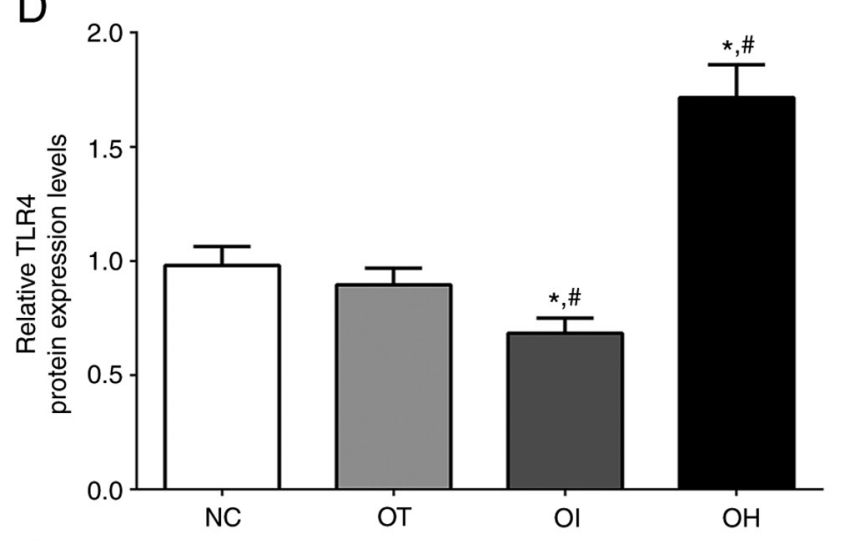

$\mathrm{F}$

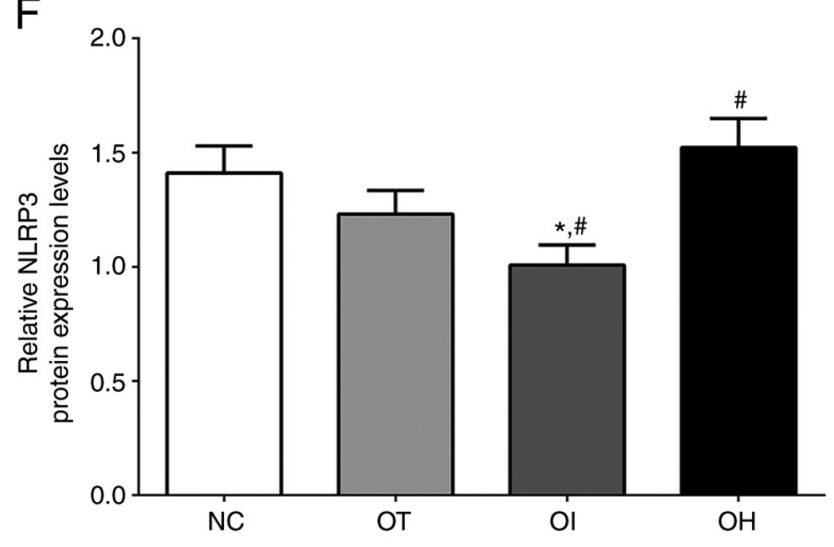

Figure 6. Protein expression levels of HO-1 regulator proteins in $\mathrm{H} 9 \mathrm{c} 2$ cells using western blot method. (A) Western blotting analysis and quantitative analysis of (B) HMGB1, (C) TLR2, (D) TLR4, (E) IL-1 $\beta$ and (F) NLRP3 in H9c2 cells. Data are presented as the mean \pm SD. Each experiment was repeated three times independently. ${ }^{*} \mathrm{P}<0.05$ vs. NC group. ${ }^{~} \mathrm{P}<0.05$ vs. OT group. DHE, dehydrocostus lactone; TXNIP, thioredoxin-interacting protein; $\mathrm{NC}$, negative control; OT, DHE treatment group; OI, DHE treatment combined with TXNIP inhibition group; OH, DHE treatment combined with TXNIP overexpression group; Nrf2, nuclear factor erythroid 2-related factor 2; HO-1, heme oxygenase-1; Keap1, Kelch-like ECH-associated protein 1; MW, molecular weight.

The expression of NLRP3 in these groups was significantly decreased in OI group compared with NC and OT group $(\mathrm{P}<0.05)$.

These results indicated that TXNIP inhibition reduced the protein expression levels of inflammation-related molecules.

Concentrationofinflammation-relatedandoxidation-reduction related factors in serum samples of mice and cultured medium of H9c2 cells. The concentrations of iNOS, which is related to the oxidative-reduction process, and COX-2, CCL9, CXCL1, CXCL9 and CXCL11 which were critical for the activation of inflammation process, in culture medium of $\mathrm{H} 9 \mathrm{c} 2$ cells of $\mathrm{NC}$,
OT, OI and OH group was quantified using ELISA method and the results are presented in Fig. 8. The concentration of iNOS in $\mathrm{NC}, \mathrm{OT}$, OI and $\mathrm{OH}$ group of $\mathrm{H} 9 \mathrm{c} 2$ cells was significantly increased in OI and OT group compared with NC group $(\mathrm{P}<0.05)$, and was significantly increased in OI group and significantly decreased in $\mathrm{OH}$ group compared with OT group $(\mathrm{P}<0.05)$. The concentration of COX-2 in these groups was significantly decreased in OT and OI group compared with NC group $(\mathrm{P}<0.05)$, and was significantly decreased in OI group compared with OT group $(\mathrm{P}<0.05)$. The concentration of CCL9 in these groups was significantly decreased in OT and OI group compared with NC group $(\mathrm{P}<0.05)$, and was significantly decreased in OI group compared with OT group 
A

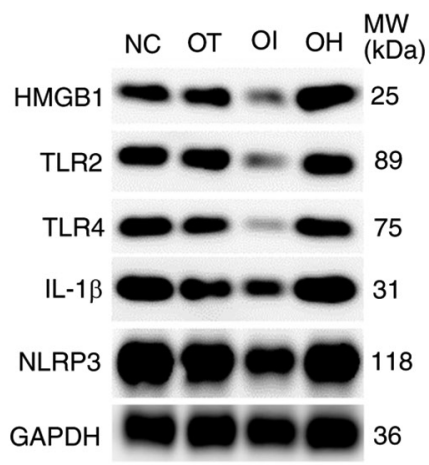

C

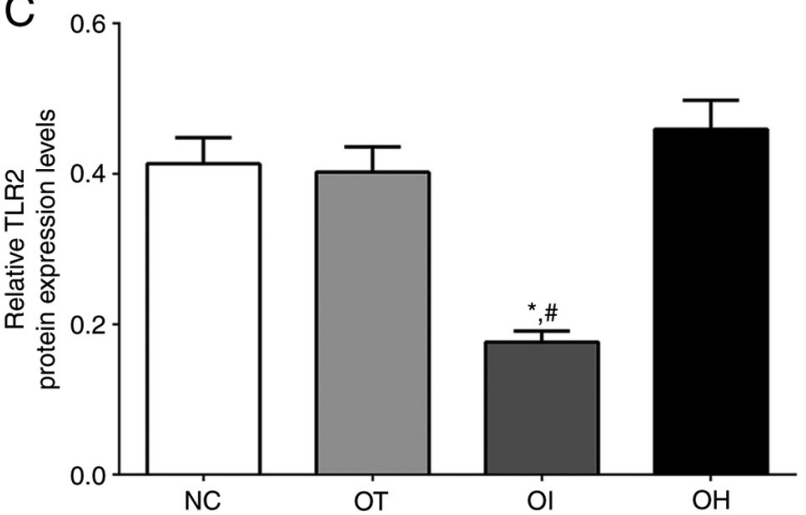

E

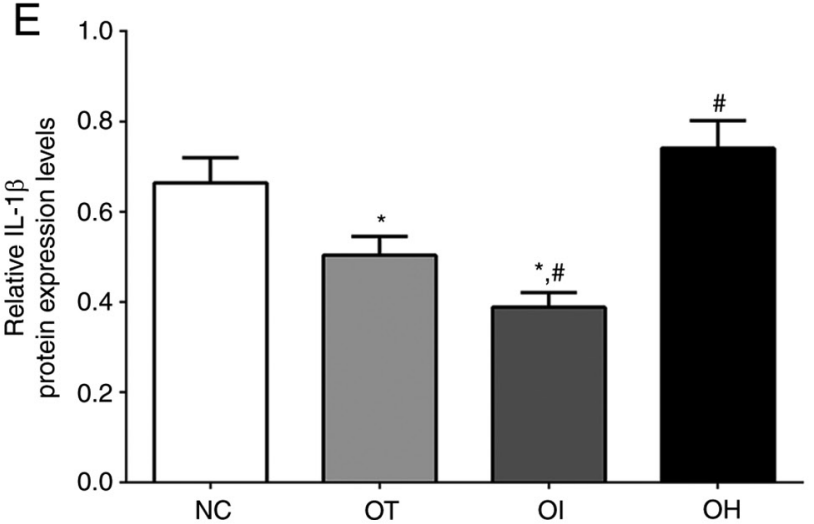

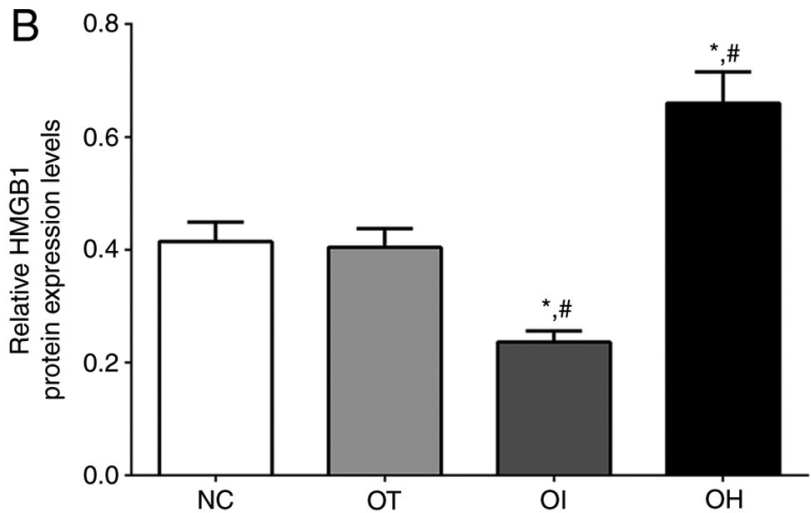
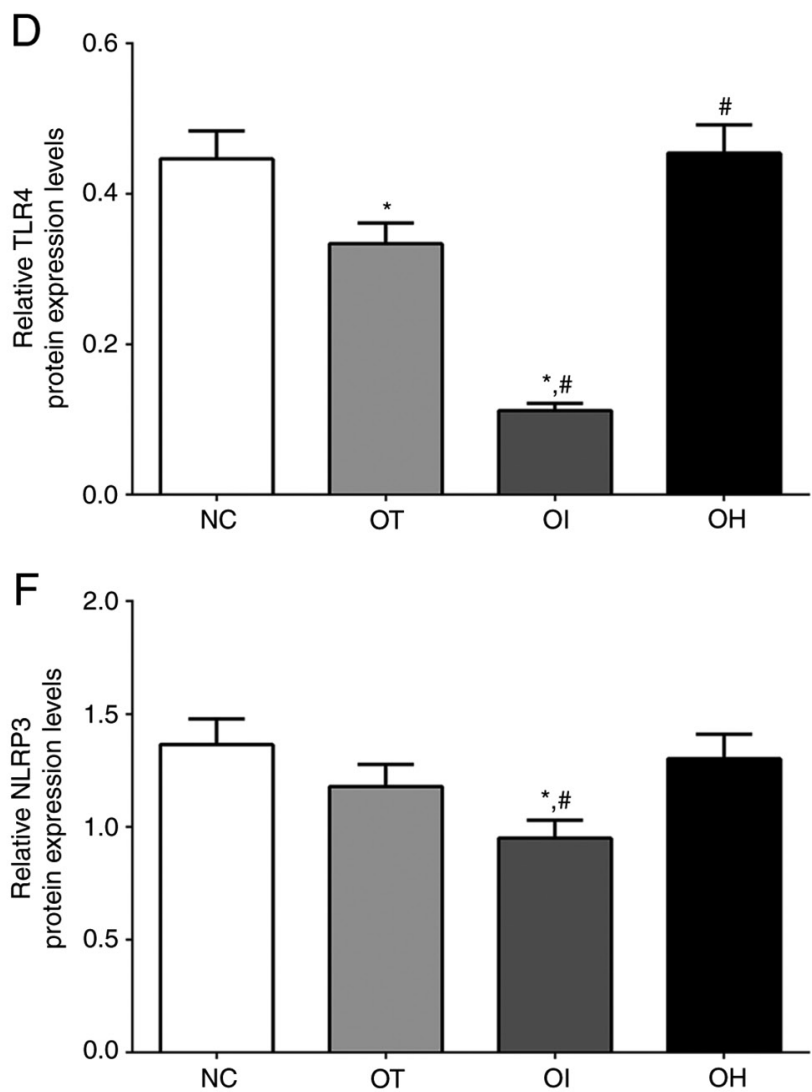

Figure 7. Expression of pro-inflammation proteins in mouse heart tissues using western blot method. (A) Western blotting analysis and quantitative analysis of (B) HMGB1, (C) TLR2, (D) TLR4, (E) IL-1 $\beta$ and (F) NLRP3 in H9c2 cells. Data are presented as the mean \pm SD. Each experiment was repeated three times independently. "P<0.05 vs. NC group. ${ }^{*} \mathrm{P}<0.05$ vs. OT group. DHE, dehydrocostus lactone; TXNIP, thioredoxin-interacting protein; NC, negative control; OT, DHE treatment group; OI, DHE treatment combined with TXNIP inhibition group; OH, DHE treatment combined with TXNIP overexpression group; TLR, toll-like receptor; HMGB1, high mobility group protein B1; NLRP3, NOD-, LRR- and pyrin domain-containing protein 3; MW, molecular weight.

$(\mathrm{P}<0.05)$. The changing in concentration of CXCL1 and CXCL9 in these groups presented a similar trend with CCL9 $(\mathrm{P}<0.05)$. And the concentration of CXCL11 in these groups was significantly decreased in OI group compared with NC and OT group $(\mathrm{P}<0.05)$.

As reported in Fig. 9, The concentration of iNOS in $\mathrm{NC}$, OT, OI and $\mathrm{OH}$ group of heart tissues was significantly increased in OI group compared with $\mathrm{NC}$ and OT group $(\mathrm{P}<0.05)$. The concentration of COX-2 in these groups was significantly decreased in OT and OI group compared with NC group $(\mathrm{P}<0.05)$, and was significantly decreased in OI group compared with OT group $(\mathrm{P}<0.05)$. The concentration of CCL9 and CXCL1 in these groups presented a similar trend with COX-2 $(\mathrm{P}<0.05)$. The concentration of CXCL9 and CXCL11 in these groups was significantly decreased in OI group compared with NC and OT group $(\mathrm{P}<0.05)$.

These results indicated that DHE treatment decreased the secretion of inflammatory response-related factors and the knockout of TXNIP significantly enhanced this trend compared with control group.

\section{Discussion}

$\mathrm{HF}$ affects more than 5.7 million people in the US, according to previous data (21). In 2013, nearly 500,000 new cases occurred in people $>55$ years (22). DHE is obtained from Chinese herbs and can be used in the treatment of various diseases, such as liver cancer, colorectal cancer and leukemia $(23,24)$. TXNIP, an 
A

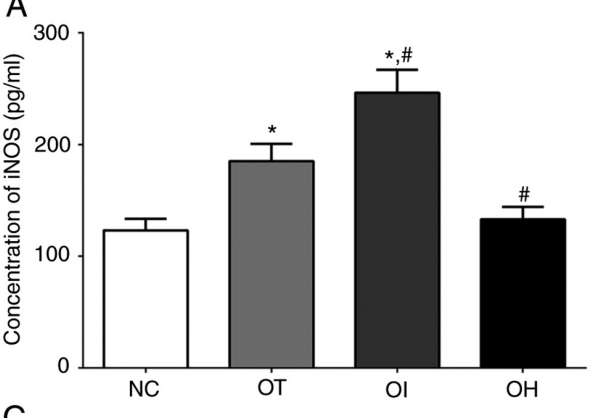

C
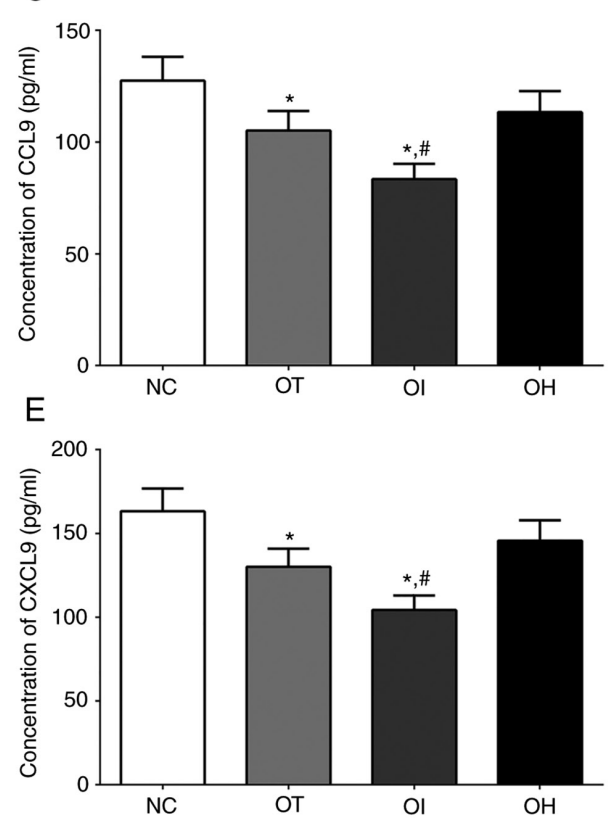

$\mathrm{B}$

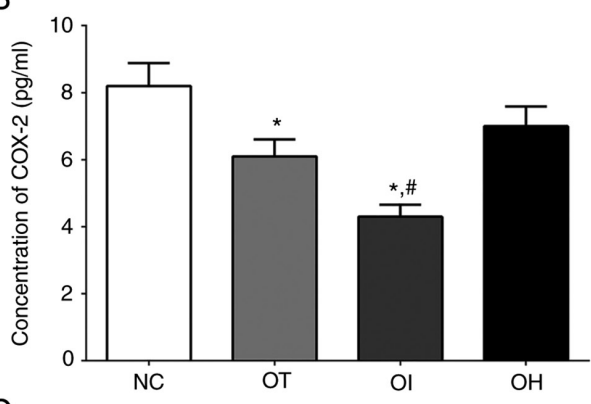

D
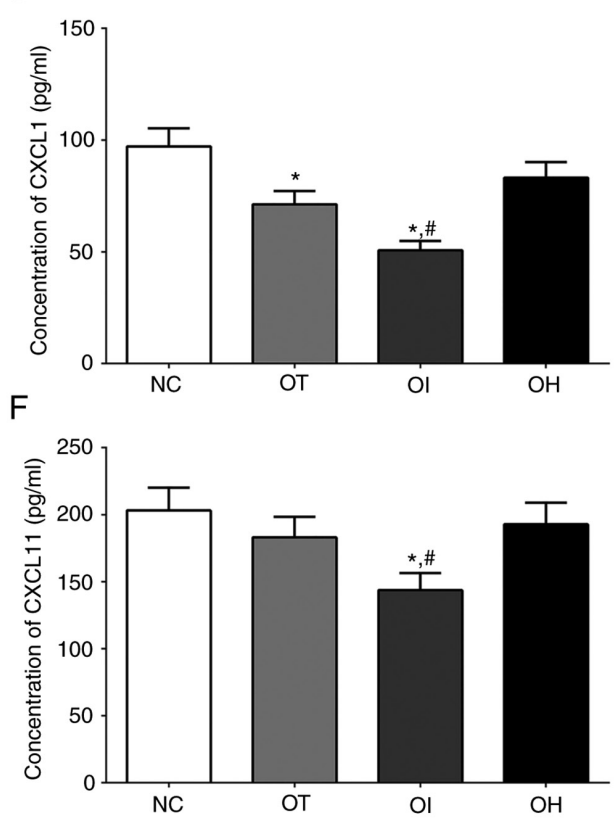

Figure 8. Detection of inflammation and oxidative-reduction related factors in H9c2 cells using ELISA method. (A) iNOS, (B) COX-2, (C) CCL9, (D) CXCL1, (E) CXCL9 and (F) CXCL11 in the culture medium of H9c2 cells. Data are presented as the mean \pm SD. Each experiment was repeated three times independently. ${ }^{*} \mathrm{P}<0.05$ vs. NC group. ${ }^{\#} \mathrm{P}<0.05$ vs. OT group. DHE, dehydrocostus lactone; TXNIP, thioredoxin-interacting protein; NC, negative control; OT, DHE treatment group; OI, DHE treatment combined with TXNIP inhibition group; OH, DHE treatment combined with TXNIP overexpression group; iNOS, inducible nitric oxide synthase; COX-2, cyclooxygenase-2; CCL9, C-C motif ligand 9; CXCL, chemokine C-X-C motif ligand.

endogenous inhibitor of thioredoxin, serves an important role in the resistance to oxidative stress induced by extracellular stimulations, including reactive oxygen species and hypoxia (25).

Under inflammatory conditions, TNF- $\alpha$ and the expression of other inflammation-related cytokines are induced by coagulation factors, such as factor VII and XI, further inducing the formation of complexes with factor VII and resulting in the activation of thrombin (26). Moreover, factor Xa, thrombin and the tissue factor-factor VII complex can increase the expression of TNF- $\alpha$ and other proinflammatory cytokines (27), promoting the blood coagulation process. Furthermore, factor $\mathrm{Xa}$ and thrombin directly affect the function of vascular cells (27) via protease-activated receptors and the nitric oxide (NO)/cGMP signaling pathway (28). The NO/cGMP signaling pathway has numerous effects on the vasculature and dysfunction of this signaling pathway leads to a reduction in cGMP production, which results in the occurrence of cardiovascular diseases (29). A previous study also indicated that the synthesis of NO inhibited the activity of $\mathrm{TF}$ (30) and prevented the formation of thrombi in circulation via its vasodilator and anti-aggregatory ability (31). The present study demonstrated that DHE significantly inhibited the expression of inflammation-related factors, including IL-1,
IL-6, IL-10, COX-2 and TNF- $\alpha$ and had an inhibitory effect on the activation of the inflammatory response. Furthermore, the present study reported that DHE increased the expression levels of iNOS, which contributes to the protective effect of DHE.

TLRs are divided into two groups according to their cellular distribution: The cell membrane group (TLR1, 2, 4, 5 and 6) and the endosome membrane within the cell group (TLR3, 7, 8 and 9) (32). The transduction of cellular signals via TLRs to the nucleus leads to the activation of innate and adaptive immune responses via the myeloid differentiation primary response 88-dependent pathway and the Toll/IL-1 receptor domain-containing adapter-inducing IFN- $\beta$-dependent pathway, leading to the activation of the NF- $\mathrm{B}$ signaling pathway (33). Under extracellular stimulation, the $N F-\kappa B$ signaling pathway is activated via TLRs, nod-like receptors or other cytokine receptors. Activation of the $\mathrm{NF}-\kappa \mathrm{B}$ signaling pathway further leads to the activation of NLRP3, initiating inflammasome activation (34). The NLRP3 inflammasome can recognize numerous stimuli and responds to endogenous factors that can lead to cellular damage, including uric acid crystals, drusen and extracellular ATP $(35,36)$. TLR activation also induces the expression of pro-IL-1 $\beta$ (37). In the present study, the activation 
A

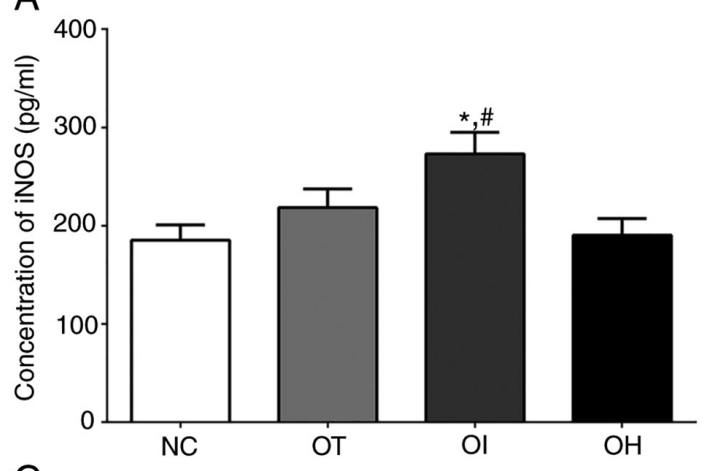

C

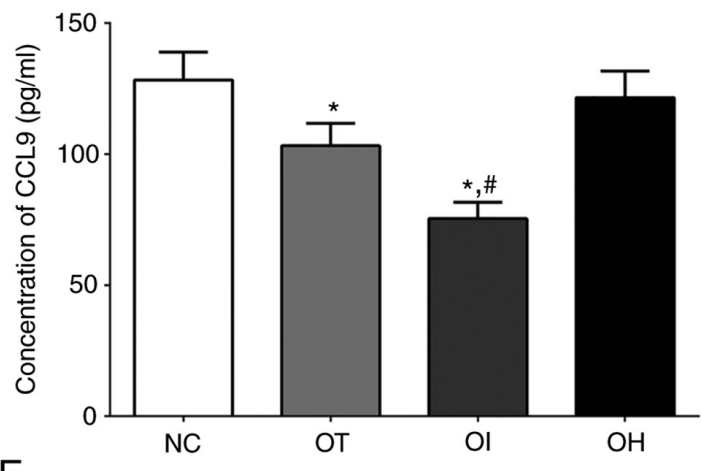

E

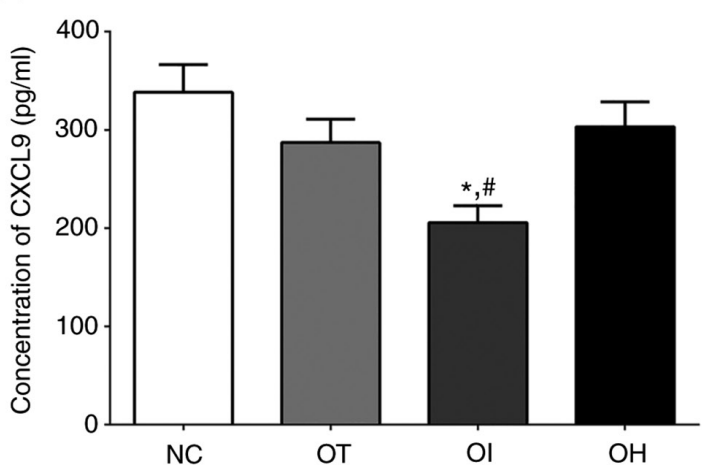

$\mathrm{B}$
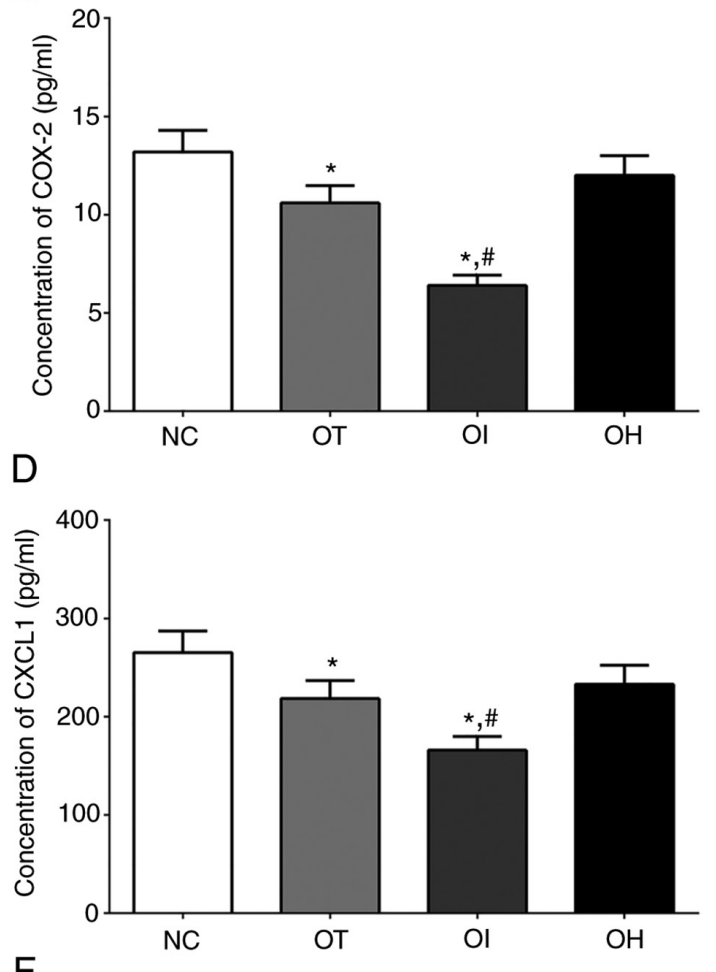

$\mathrm{F}$

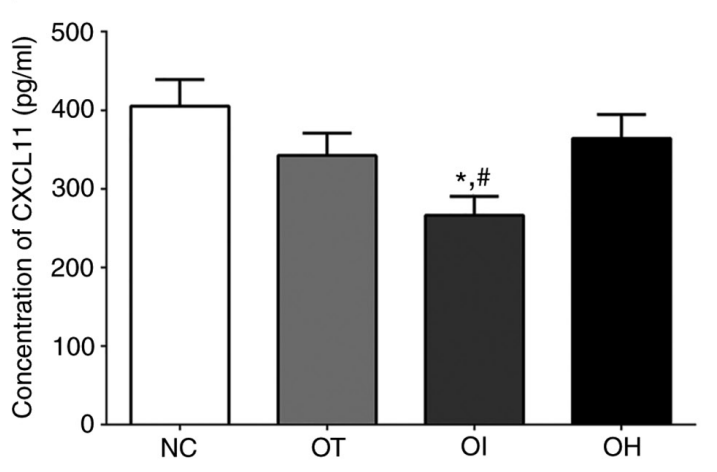

Figure 9. Detection of inflammation and oxidative-reduction related factors in heart tissue of mice using ELISA method (A) iNOS, (B) COX-2, (C) CCL9, (D) CXCL1, (E) CXCL9 and (F) CXCL11 in mouse heart tissues. Data are presented as the mean \pm SD. Each experiment was repeated three times independently. ${ }^{*} \mathrm{P}<0.05$ vs. NC group. ${ }^{*} \mathrm{P}<0.05$ vs. OT group. DHE, dehydrocostus lactone; TXNIP, thioredoxin-interacting protein; NC, negative control; OT, DHE treatment group; OI, DHE treatment combined with TXNIP inhibition group; OH, DHE treatment combined with TXNIP overexpression group; iNOS, inducible nitric oxide synthase; COX-2, cyclooxygenase-2; CCL9, C-C motif ligand 9; CXCL, chemokine C-X-C motif ligand.

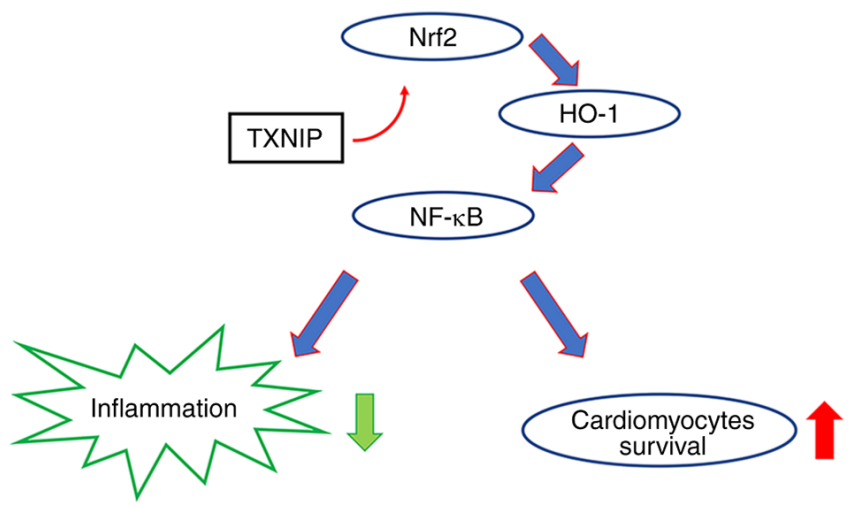

Figure 10. Schematic diagram of the experimental hypothesis. Knockout of TXNIP promotes the activation of HO-1 through the Nrf2 pathway, leading to a reduction in inflammation activation. TXNIP knockout therefore exerted a protective role in cardiomyocytes. Nrf2, nuclear factor erythroid 2-related factor 2; HO-1, heme oxygenase-1; TXNIP, thioredoxin-interacting protein. of these factors upon HF was inhibited after DHE treatment and was even lower after TNXIP inhibition, indicating that the activation of the inflammatory response in H9c2 cardiomyocytes and heart tissues was inhibited, and presented a protective role.

HO-1 is an enzyme presenting cytoprotective and antioxidant effects (38). The expression of HO-1 is regulated at the transcriptional level via the regulation of $\mathrm{Nrf} 2$ (39). Under normal conditions, Nrf2 binds to Keap1 (40) and when oxidated Nrf2 is released from Keap1 and translocated into the nucleus, further binding with antioxidant response element sequences of the HO-1 promoter region (41). The activation of $\mathrm{HO}-1$ further leads to the activation of $\mathrm{NF}-\kappa \mathrm{B}$, which inhibits the expression of IL-6, TNF- $\alpha$ and IL- $1 \beta$ and subsequently the inflammatory response process (42). In the present study, the protein expression levels of HO-1 were significantly increased after treatment with DHE combined with TXNIP konckout, presenting a protective effect (Fig. 10). 
Although the results indicated that TXNIP inhibition contributed to the therapeutic effect of DHE, the present study has numerous limitations. The detailed mechanism of how TXNIP inhibition promoted the effect of DHE is not fully understood and it should be explored in future experiments. The Nrf2/HO-1 signaling pathway expression in TXNIP overexpression and knockout groups without DHE treatment was detected using RT-qPCR only; in further experiments, the protein levels should also be detected. Other methods could contribute to explore the aforementioned mechanisms, such as mass spectrometry, RNA sequencing and chromatin immunoprecipitation sequencing. Clinical samples would also help understand the association between TXNIP and DHE, and the mechanism of TXNIP knockout promoting the function of DHE.

\section{Acknowledgements}

Not applicable.

\section{Funding}

No funding was received.

\section{Availability of data and materials}

The datasets used and/or analyzed during the current study are available from the corresponding author on reasonable request.

\section{Authors' contributions}

$\mathrm{XZ}$ and $\mathrm{CC}$ performed the cell, mice, protein and nucleic acid experiments, and wrote the manuscript. YH designed the experiment and revised the manuscript. XZ and $\mathrm{YH}$ confirm the authenticity of all the raw data. All authors have read and approved the final manuscript.

\section{Ethics approval and consent to participate}

The present study was carried out in strict accordance with the recommendations in the Guide for the Care and Use of Laboratory Animals of the National Institutes of Health (17). The present protocol and experiments were approved by the Ethics Committee of Animal Experiments of Anqiu People's Hospital (Anqiu, China; approval no. IACUC-20200920).

\section{Patient consent for publication}

Not applicable.

\section{Competing interests}

The authors declare that they have no competing interests.

\section{References}

1. Virani SS, Alonso A, Benjamin EJ, Bittencourt MS, Callaway CW, Carson AP, Chamberlain AM, Chang AR, Cheng S, Delling FN, et al: Heart disease and stroke statistics-2020 Update: A report from the American Heart association. Circulation 141: e139-e596, 2020.
2. Hofmann U and Frantz S: How can we cure a heart 'in flame'? A translational view on inflammation in heart failure. Basic Res Cardiol 108: 356, 2013.

3. Ammirati E, Cannistraci CV, Cristell NA, Vecchio V, Palini AG, Tornvall P, Paganoni AM, Miendlarzewska EA, Sangalli LM, Monello A, et al: Identification and predictive value of interleukin-61 interleukin-101 and interleukin-62 interleukin-101 cytokine patterns in ST-elevation acute myocardial infarction. Circ Res 111: 1336-1348, 2012.

4. Bozkurt B, Torre-Amione G, Warren MS, Whitmore J, Soran OZ, Feldman AM and Mann DL: Results of targeted anti-tumor necrosis factor therapy with etanercept (ENBREL) in patients with advanced heart failure. Circulation 103: 1044-1047, 2001.

5. Taniguchi M, Kataoka T, Suzuki H, Uramoto M, Ando M, Arao K, Magae J, Nishimura T, Otake N and Nagai K: Costunolide and dehydrocostus lactone as inhibitors of killing function of cytotoxic T lymphocytes. Biosci Biotechnol Biochem 59: 2064-2067, 1995.

6. Yuuya S, Hagiwara H, Suzuki T, Ando M, Yamada A, Suda K, Kataoka T and Nagai K: Guaianolides as immunomodulators. Synthesis and biological activities of dehydrocostus lactone, mokko lactone, eremanthin, and their derivatives. J Nat Prod 62: 22-30, 1999.

7. Jeong GS, Pae HO, Jeong SO, Kim YC, Kwon TO, Lee HS, Kim NS, Park SD and Chung HT: The alpha-methylenegamma-butyrolactone moiety in dehydrocostus lactone is responsible for cytoprotective heme oxygenase-1 expression through activation of the nuclear factor E2-related factor 2 in HepG2 cells. Eur J Pharmacol 565: 37-44, 2007.

8. Zhang HW, Liu YM, Fang X, Gu L, Luo C, Chen L and Wang Q: Vitamin $\mathrm{D}_{3}$ protects mice from Diquat-induced oxidative stress through the NF- $\kappa \mathrm{B} / \mathrm{Nrf} 2 / \mathrm{HO}-1$ signaling pathway. Oxid Med Cell Longev 2021: 6776956, 2021.

9. Wu YX, Jiang FJ, Liu G, WangYY, Gao ZQ, Jin SH, Nie YJ, Chen D, Chen JL and Pang QF: Dehydrocostus lactone attenuates methicillin-resistant staphylococcus Aureus-induced inflammation and acute lung injury via modulating macrophage polarization. Int J Mol Sci 22: 9754, 2021.

10. Kim HR, Kim JM, Kim MS, Hwang JK, Park YJ, Yang SH, Kim HJ, Ryu DG, Lee DS, Oh H, et al: Saussurea lappa extract suppresses TPA-induced cell invasion via inhibition of NF- $\kappa$ B-dependent MMP-9 expression in MCF-7 breast cancer cells. BMC Complement Altern Med 14: 170, 2014.

11. Kim EJ, Lim SS, Park SY, Shin HK, Kim JS and Park JH: Apoptosis of DU145 human prostate cancer cells induced by dehydrocostus lactone isolated from the root of Saussurea lappa. Food Chem Toxicol 46: 3651-3658, 2008.

12. Nie Y, Wang Z, Chai G, Xiong Y, Li B, Zhang H, Xin R, Qian X, Tang Z, Wu J and Zhao P: Dehydrocostus lactone suppresses LPS-induced acute lung injury and macrophage activation through NF- $\mathrm{KB}$ signaling pathway mediated by p38 MAPK and Akt. Molecules 24: 1510, 2019.

13. Masutani H, Yoshihara E, Masaki S, Chen Z and Yodoi J: Thioredoxin binding protein (TBP)-2/Txnip and alpha-arrestin proteins in cancer and diabetes mellitus. J Clin Biochem Nutr 50: 23-34, 2012.

14. Dai X, Liao R, Liu C, Liu S, Huang H, Liu J, Jin T, Guo H, Zheng Z, Xia M, et al: Epigenetic regulation of TXNIP-mediated oxidative stress and NLRP3 inflammasome activation contributes to SAHH inhibition-aggravated diabetic nephropathy. Redox Biol 45: 102033, 2021.

15. Neville ES, Ophir S and Zhang F: Improved vectors and genome-wide libraries for CRISPR screening. Nat Methods 11: 783-784, 2014.

16. Wen JX, Zhang L, Liu H, Wang J, Li J, Yang Y, Wang Y, Cai H, Li R and Zhao Y: Salsolinol attenuates doxorubicin-induced chronic heart failure in rats and improves mitochondrial function in H9c2 cardiomyocytes. Front Pharmacol 10: 1135, 2019.

17. Wang K, Zhou A, Ruan M, Jin Z, Lu J, Wang Q and Lu C: Dehydrocostus lactone suppresses ox-LDL-induced attachment of monocytes to endothelial cells. Am J Transl Res 11: 6159-6169, 2019.

18. National Research Council (US) Institute for Laboratory Animal Research. Guide for the Care and Use of Laboratory Animals. Washington (DC), National Academies Press (US), 1996.

19. Wang X, Gao Y, Tian Y, Liu X, Zhang G, Wang Q, Xie W, Liu K, Qian Q and Wang Q: Integrative serum metabolomics and network analysis on mechanisms exploration of Ling-Gui-Zhu-Gan Decoction on doxorubicin-induced heart failure mice. J Ethnopharmacol 250: 112397, 2020. 
20. Livak KJ and Schmittgen TD: Analysis of relative gene expression data using real-time quantitative PCR and the 2(-Delta Delta C(T)) method. Methods 25: 402-408.

21. Freddy AS and David G: Cardiac contractility modulation: A novel approach for the treatment of heart failure. Heart Fail Rev 21: 645-660, 2016.

22. Benjamin EJ, Blaha MJ, Chiuve SE, Cushman M, Das SR, Deo R, de Ferranti SD, Floyd J, Fornage M, Gillespie C, et al: Heart disease and stroke statistics-2017 update: A report from the American Heart Association. Circulation 135: e146-e603, 2017.

23. Peng Z, Wang Y, Fan J, Lin X, Liu C, Xu Y, Ji W, Yan C and Su C: Costunolide and dehydrocostuslactone combination treatment inhibit breast cancer by inducing cell cycle arrest and apoptosis through c-Myc/p53 and AKT/14-3-3 pathway. Sci Rep 7: 41254, 2017.

24. Sun X, Kang H, Yao Y, Chen H, Sun L, An W, Jiang E, Wang S and Hu X: Dehydrocostus lactone suppressed the proliferation, migration, and invasion of colorectal carcinoma through the downregulation of eIF4E expression. Anticancer Drugs 26: 641-648, 2015

25. Han X, Wu YC, Meng M, Sun QS, Gao SM and Sun H: Linarin prevents LPS-induced acute lung injury by suppressing oxidative stress and inflammation via inhibition of TXNIP/NLRP3 and NF- $\kappa$ B pathways. Int J Mol Med 42: 1460-1472, 2018.

26. Iannucci J, Renehan W and Grammas P: Thrombin, a mediator of coagulation, inflammation, and neurotoxicity at the neurovascular interface: Implications for Alzheimer's disease. Front Neurosci 14: 762, 2020

27. Pawlinski R, Pedersen B, Kehrle B, Aird WC, Frank RD, Guha M and Mackman N: Regulation of tissue factor and inflammatory mediators by Egr-1 in a mouse endotoxemia model. Blood 10: 3940-3947, 2003.

28. Scotton CJ, Krupiczojc MA, Königshoff M, Mercer PF, Lee YC, Kaminski N, Morser J, Post JM, Maher TM, Nicholson AG, et al: Increased local expression of coagulation factor $\mathrm{X}$ contributes to the fibrotic response in human and murine lung injury. J Clin Invest 1199: 2550-2563, 2009.

29. Motley ED, Eguchi K, Patterson MM, Palmer PD, Suzuki H and Eguchi S: Mechanism of endothelial nitric oxide synthase phosphorylation and activation by thrombin. Hypertension 49 : 577-583, 2007.

30. Stasch JP and Hobbs AJ: NO-independent, haem-dependent soluble guanylate cyclase stimlators. Handb Exp Pharmacol: 277-308, 2009 doi: 10.1007/978-3-540-68964-5_13.
31. Yang Y and Loscalzo J: Regulation of tissue factor expression in human microvascular endothelial cells by nitric oxide. Circulation 101: 2144-2148, 2000.

32. Tschudi MR and Luscher TF: Nitric oxide: The endogenous nitrate in the cardiovascular system. Herz 21: 50-60, 1996.

33. Rakoff-Nahoum S and Medzhitov R: Toll-like receptors and cancer. Nat Rev Cancer 9: 57-63, 2009.

34. Piras V and Selvarajoo K: Beyond MyD88 and TRIF pathways in Toll-like receptor signaling. Front Immunol 5: 70, 2014.

35. Bauernfeind FG, Horvath G, Stutz A, Alnemri ES, MacDonald K, Speert D, Fernandes-Alnemri T, Wu J, Monks BG, Fitzgerald KA, et al: Cutting edge: NF-kappaB activating pattern recognition and cytokine receptors license NLRP3 inflammasome activation by regulating NLRP3 expression. J Immunol 183: 787-791, 2009.

36. Franchi L, Muñoz-Planillo R and Núñez G: Sensing and reacting to microbes through the inflammasomes. Nat Immunol 13: 325-332, 2012.

37. Mariathasan S, Weiss DS, Newton K, McBride J, O'Rourke K, Roose-Girma M, Lee WP, Weinrauch Y, Monack DM and Dixit VM: Cryopyrin activates the inflammasome in response to toxins and ATP. Nature 440: 228-232, 2006.

38. Franchi L, Eigenbrod T and Núñez G: Cutting edge: TNF-alpha mediates sensitization to ATP and silica via the NLRP3 inflammasome in the absence of microbial stimulation. J Immunol 183: 792-796, 2009.

39. Kapitulnik J: Bilirubin: An endogenous product of heme degradation with both cytotoxic and cytoprotective properties. Mol Pharmacol 66: 773-779, 2004.

40. Srisook K, Kim C and Cha YN: Molecular mechanisms involved in enhancing HO-1 expression: De-repression by heme and activation by Nrf2, the 'one-two' punch. Antioxid Redox Signal7: 1674-1687, 2005

41. Farombi EO and Surh YJ: Heme oxygenase-1 as a potential therapeutic target for hepatoprotection. J Biochem Mol Biol 39: 479-491, 2006

42. Owuor ED and Kong AN: Antioxidants and oxidants regulated signal transduction pathways. Biochem Pharmacol 64: 765-770, 2002.

(i) This work is licensed under a Creative Commons Attribution-NonCommercial-NoDerivatives 4.0 International (CC BY-NC-ND 4.0) License. 